\title{
Dopamine modulation of two delayed rectifier potassium currents in a small neural network
}

\section{Matthias Gruhn', John Guckenheimer ${ }^{2,}$ Bruce Land $^{1}$, and Ronald M.Harris-Warrick ${ }^{1}$}

\author{
Cornell University \\ ${ }^{1}$ Department of Neurobiology and Behavior \\ Seeley G. Mudd Hall \\ ${ }^{2}$ Department of Mathematics \\ Malott Hall \\ Ithaca, NY, 14853
}

running title: Dopamine effect on $\mathrm{I}_{\mathrm{K}(\mathrm{V})}$

Corresponding author:

Dr.Matthias Gruhn

Universität zu Köln

Zoologisches Institut

Tierphysiologie

Weyertal 119

50923 Köln

Germany

\# office: $++49-(0) 221-470-3132$

\# lab: ++49-(0)221-470-3122

Fax\#: ++49-(0)221-470-4889

e-mail: mgruhn@uni-koeln.de

Number of figures and tables: 8 figures and 2 tables, 1 equation 


\begin{abstract}
Delayed rectifier potassium currents $\left(\mathrm{I}_{\mathrm{K}(\mathrm{V})}\right)$ generate sustained, non-inactivating outward currents with characteristic fast rates of activation and deactivation and play important roles in shaping spike frequency. The pyloric motor network in the stomatogastric ganglion (STG) of the spiny lobster, Panulirus interruptus, is made up of one interneuron and 13 motor neurons of five different classes. Dopamine (DA) increases the firing frequencies of the AB, PY, LP and IC neurons and decreases the firing frequencies of the PD and VD neurons. In all 6 types of pyloric neurons, $\mathrm{I}_{\mathrm{K}(\mathrm{V})}$ is small with respect to other $\mathrm{K}^{+}$currents. It is made up of at least two TEA-sensitive components that show differential sensitivity to 4-aminopyridine (4AP) and quinidine, and have differing thresholds of activation. One saturable component is activated at potentials above $25 \mathrm{mV}$, while the second component appears at more depolarized voltages and does not saturate at voltage steps up to $+45 \mathrm{mV}$. The magnitude of the components varies among cell types but also shows considerable variation within a single type. A subset of PY neurons shows a marked enhancement in spike frequency with DA; DA evokes a pronounced reversible increase in $\mathrm{I}_{\mathrm{K}(\mathrm{V})}$ conductance of up to $30 \%$ in the PY neurons studied, and on average significantly increases both components of $\mathrm{I}_{\mathrm{K}(\mathrm{V})}$. The $\mathrm{AB}$ neuron also shows a reversible $20 \%$ increase in the steady state $\mathrm{I}_{\mathrm{K}(\mathrm{V})}$. DA had no effect on $\mathrm{I}_{\mathrm{K}(\mathrm{V})}$ in PD, LP, VD and IC neurons. The physiological roles of these currents and their modulation by DA are discussed.
\end{abstract}

Keywords: $\mathrm{I}_{\mathrm{K}(\mathrm{V})}$, STG, pyloric network, Panulirus interruptus 


\section{Introduction}

Non-inactivating delayed rectifier-type potassium channels generate a current, $\mathrm{I}_{\mathrm{K}(\mathrm{V})}$, that is responsible for the fast repolarization of the membrane potential following action potentials in spiking neurons. It helps to determine the spike width and post-spike hyperpolarization, and can help shape the maximal spike frequency of neurons (Rudy and McBain 2001; Shevchenko et al. 2004). Recently, $I_{K(V)}$ channels have also been implicated in the prevention of AP generation in amacrine cells in the mouse retina and even in apoptosis-related $\mathrm{K}^{+}$efflux (Pal et al. 2003; Ozaita et al. 2004). In vertebrates, $\mathrm{I}_{\mathrm{K}(\mathrm{V})}$ is encoded by members of the $\mathrm{Kv} 1, \mathrm{Kv} 2$ and $\mathrm{Kv} 3$ subfamilies of potassium channel genes (Coetzee et al, 1999; Dodson and Forsythe 2004), and in invertebrates by the shab, shaw, and some splice variants of the shaker subfamilies of potassium channel genes (Covarrubias et al. 1991; Tsunoda and Salkoff 1995a,b; Kim et al. 1998). Noninactivating delayed rectifier channels are expressed in the somatodendritic as well as in the axonal and synaptic compartments of both mammalian and invertebrate cells (Martinez-Padron and Ferrus 1997; Dodson and Forsythe 2004). Within the same cell or cell population, different types of delayed rectifier channels can be expressed in parallel, and create specific mixed conductance/voltage relationships (Covarrubias et al. 1991; Baranauskas et al. 1999; Rothman and Manis 2003).

The stomatogastric ganglion (STG) of the spiny lobster Panulirus interruptus has been a valuable model system for the study of ionic currents and their contribution to shaping the rhythmic output of a neural network (Hartline 1979; Graubard and Hartline 1991; Golowasch et al, 1992; Harris-Warrick et al. 1992; Harris-Warrick 2002; Calabrese 2004). The STG contains the pyloric network of 14 neurons that controls rhythmic contractions of the posterior crustacean foregut (Harris-Warrick et al 1992). In recent years, we have accumulated knowledge about many of the currents that take part in determining the unique firing properties of neurons in this small network, including a rapidly inactivating potassium (A) current (Graubard and Hartline 1991; Golowasch and Marder 1992; Baro et al. 1996b; Kim et al. 1997), the H-current ( $\mathrm{I}_{\mathrm{h}}$ ) (Harris-Warrick et al. 1995b; Peck et al. 2004), voltage-sensitive calcium current (Johnson et al. 2003) and a 
Ca-dependent $\mathrm{K}^{+}$-current (Graubard and Hartline 1991; Kloppenburg et al. 1999). A detailed analysis of the non-inactivating delayed rectifier-type current in the STG, however, is still missing (Kloppenburg et al. 1999).

All of the currents mentioned above are subject to modulation. Neuromodulators such as biogenic amines or neuropeptides play crucial roles in shaping the output of the pyloric network (Ayali and Harris-Warrick 1999; Marder and Thirumalai 2002). Dopamine (DA), for example, modulates the motor patterns of the pyloric circuit in the STG by its differential effect on pyloric neurons and synapses (Harris-Warrick et al. 1998). Generally, in the presence of DA, the cycle frequency of the pyloric circuit is modestly decreased (Ayali and Harris-Warrick 1999). At the same time, the spike frequency of several neurons is increased, while other neurons are inhibited (Flamm and HarrisWarrick1986a,b). The observed changes are in part due to modulatory effects on $\mathrm{I}_{\mathrm{A}}$, $\mathrm{I}_{\mathrm{K}(\mathrm{Ca})}, \mathrm{I}_{\mathrm{h}}$ and $\mathrm{I}_{\mathrm{Ca}}$ in the different neurons (Harris-Warrick et al. 1995a,b; Kloppenburg et al. 1999; Peck et al. 2001; Johnson et al. 2003), as well as its effects on synaptic transmission at chemical and electric synapses (Johnson and Harris-Warrick 1990; Johnson et al. 1995; Ayali et al. 1998).

Here we describe the properties of the delayed-rectifier type current $\mathrm{I}_{\mathrm{K}(\mathrm{V})}$ in the pyloric network of the STG and its cell specific modulation by dopamine. Partial results of this work have been published in abstract form (Gruhn and Harris-Warrick 2003; Gruhn et al. 2004). 


\section{Materials and Methods}

\section{Animals}

Spiny lobsters (Panulirus interruptus) were obtained from Don Tomlinson Fishing Co. (San Diego, CA) and maintained at $16^{\circ} \mathrm{C}$ in artificial seawater tanks for $\leq 4$ weeks. Chemicals, unless stated otherwise, were obtained from Sigma Chemicals (St. Louis, MO).

\section{Dissection and identification of neurons}

Animals were anesthetized on ice for at least 30min. The stomatogastric ganglion (STG) was dissected along with the commissural and oesophageal ganglia, as described by Selverston et al. (1976), and pinned out in a Sylgard-coated dish. The desheathed preparation was continuously superfused with $16^{\circ} \mathrm{C}$ oxygenated Panulirus saline at $3 \mathrm{ml} / \mathrm{min}$, with the following composition in $\mathrm{mM}: 479 \mathrm{NaCl}, 12.8 \mathrm{KCl}, 13.7 \mathrm{CaCl}_{2}, 3.9$ $\mathrm{Na}_{2} \mathrm{SO}_{4}, 10 \mathrm{MgSO}_{4}, 2$ glucose, 11.1 Tris-base, and 5.1 maleic acid, pH 7.35 (Mulloney and Selverston 1974). Extracellular recordings from identified motor nerves were made with bipolar suction electrodes. Individual pyloric neurons were identified through intracellular recording with glass microelectrodes $\left(10-20 \mathrm{M}^{\mathrm{\prime}} \Omega ; 3 \mathrm{mM} \mathrm{KCl}\right)$. Criteria for identification were a 1:1 correlation of intra- and extracellular spikes in pyloric neurons and identified motor nerves, characteristic phasing of neuron activity in the pyloric motor pattern; and the characteristic membrane potential oscillations in the pyloric rhythm.

\section{Electrical recordings in single pyloric neurons and block of currents}

Pyloric neurons were isolated from most synaptic input by the application of $0.1 \mu \mathrm{M}$ TTX to block action potential propagation and neuromodulatory input from other ganglia, and $5 \mu \mathrm{M}$ picrotoxin (PTX), to block glutamatergic synapses within the pyloric network. $5 \mathrm{mM}$ $\mathrm{CsCl}$ was used to block $\mathrm{I}_{\mathrm{h}}$ and $\mathrm{I}_{\mathrm{A}}$ was removed by holding cells at $-40 \mathrm{mV}$ at which the current is inactivated. To isolate $\mathrm{I}_{\mathrm{K}(\mathrm{V})}$, the perfusion saline additionally contained $0.8 \mathrm{mM}$ $\mathrm{CdCl}_{2}$ to block $\mathrm{I}_{\mathrm{K}(\mathrm{Ca})}$ and $\mathrm{I}_{\mathrm{Ca}}$ as well as remaining synaptic inputs. This concentration appeared to block Ca-dependent currents in the LP neuron more effectively than $0.5 \mathrm{mM}$ 
$\mathrm{CdCl}_{2}$. We did not detect any signs of toxicity at this concentration, as stable recordings of $\mathrm{I}_{\mathrm{K}(\mathrm{V})}$ with constant holding currents were possible over several hours.

Two-electrode voltage clamp (TEVC) recordings were performed with an Axoclamp 2B amplifier using pClamp8 software (both Axon Instruments, Foster City, CA). For current injection, glass microelectrodes with resistance of $8-12 \mathrm{M} \Omega$ were used. Linear leak was subtracted digitally with a p/8 protocol (Armstrong and Bezanilla 1974).

\section{$I_{K v}$ characterization and DA effect}

Voltage steps of $500 \mathrm{~ms}$ length were given in $5 \mathrm{mV}$ increments between $-30 \mathrm{mV}$ and $+45 \mathrm{mV}$ from the holding potential of $-40 \mathrm{mV}$. Current amplitude was measured as steadystate current at the end of each step. The pharmacology of $\mathrm{I}_{\mathrm{K}(\mathrm{V})}$ was tested by application of 4-aminopyridine (4-AP, 4-20mM), tetraethylammonium chloride (TEA, 5-100mM) and quinidine (100- $\mu \mathrm{M}-1 \mathrm{mM})$, which were all dissolved in perfusion saline. When using 50 and $100 \mathrm{mM}$ TEA, the $\mathrm{NaCl}$ concentration was lowered to avoid a change in osmolarity. In all 4-AP experiments, recordings were started 30min after superfusing the blocker because of a temporary and reversible leak current evoked by 4-AP previously reported in PD neurons (Kloppenburg et al. 1999). TEA and quinidine were superfused for at least 10 minutes before recording their effects on $\mathrm{I}_{\mathrm{K}(\mathrm{V})}$. The dose dependence of the block was tested by superfusing 4-AP, TEA, and quinidine at a specific concentration until a stable level of block was observed, and then stepping up the blocker concentration and repeating this procedure. 4-AP-, TEA-, and quinidine-sensitive currents were analyzed after digital subtraction from control currents.

Dopamine (DA, 0.1mM) was freshly dissolved in saline containing $0.8 \mathrm{mM} \mathrm{CdCl}_{2}, 5 \mathrm{mM}$ $\mathrm{CsCl}, 0.1 \mu \mathrm{M}$ TTX and $5 \mu \mathrm{M}$ PTX immediately before application. $\mathrm{I}_{\mathrm{K}(\mathrm{V})}$ was measured before DA perfusion, 5min after beginning perfusion, and 20-30min after the end of perfusion (wash). Current was converted into conductance, g, assuming $E_{K}=-86 m V$ (Hartline and Graubard 1992). Cells showing a continuous reduction in current under control conditions or a lack of reversibility of the DA effect were discarded from the analysis. 
Conductance was normalized against conductance at the $+40 \mathrm{mV}$ step for each cell and then averaged. For the studies of blockers and DA, conductance values were normalized against the conductance of the control value at the $+40 \mathrm{mV}$ step of the same cell and then averaged. Error values throughout text and figures are given as standard deviations (SD).

\section{Mathematical separation of two components of $I_{K(V)}$}

The conductance was plotted as a function of voltage and was modeled as the sum of an initial saturable Boltzmann component and an exponential component. This was done because the data points we could reliably obtain for the second component only represented the rising phase of its Boltzmann relation and this could not be reliably fit by a second Boltzmann relation. Since the early rising phase of a Boltzmann relation resembles an exponential relationship, we used the estimated exponential to subtract the second component away and get a good Boltzmann fit for the first phase. We certainly believe that both currents represent typical channels with saturable activation, but we were unable to fit the second component with a full Boltzmann relation due to its depolarized activation range.

The analysis was performed with the following formula:

$\mathrm{g}=\mathrm{g}_{\max } /\left(1+\mathrm{e}^{((\mathrm{V}-\mathrm{V} 1 / 2) / \mathrm{s})}\right)+\mathrm{p} 1 * \mathrm{e}^{-((\mathrm{V}-45) / \mathrm{p} 2)}$

$\mathrm{g}$ and $\mathrm{V}$ are the experimental conductance and voltages, with $\mathrm{V}$ in millivolts. Five parameters were estimated from a curve-fitting process. $\mathrm{V}_{1 / 2}$ is the voltage of halfactivation of the lower threshold saturable, Boltzmann-fitted component, $\mathrm{s}$ is its slope, and $\mathrm{g}_{\max }$ its maximum conductance. $\mathrm{p} 1$ and $\mathrm{p} 2$ are parameters of the high-threshold, nonsaturable current component. They reflect the quasi-exponential activation of a current that did not start to saturate at $+45 \mathrm{mV}$ and could not be fit by a Boltzmann relation, and thus do not represent biophysically realistic parameters. Estimation of the parameters and their errors was performed by repeated nonlinear curve fits of the conductance data. The value of 45 in the second term of the equation was chosen arbitrarily to scale the value of the coefficients for the conductance so that they have values that are not too far from one; it has no intrinsic physiological meaning. 
Uncertainty of the parameter estimate could come from two sources, noise in the experimental data and failure of the curve fit to find a true minimum in the 5-dimensional parameter landscape. Parametric error estimates resulting from experimental noise were handled by formal error propagation techniques. Many repetitions allowed us to estimate the uncertainty in the parameters due to convergence of the nonlinear curve fit to false minima in the 5-dimensional parameter landscape. Generally, the uncertainty in parameters was dominated by false minima, but showed a strong central tendency clustered around certain values.

Curve fitting and error analysis were carried out using Matlab (Mathworks.com) and the Matlab Statistics toolbox, particularly the function "nlinfit". Formal error propagation was estimated using the Statistics toolbox routine "nlparci". Full details and the program are available at http://www.nbb.cornell.edu/neurobio/land/PROJECTS/MKG23curvefit/index.html. The curve fit was performed several hundred times for each data set, using different starting estimates for the parameters. Each of five starting parameter estimates was drawn from a normal distribution with a mean determined through initial fitting with Kaleidagraph (Vers. 3.09, Synergy Software) and with a standard deviation of $30 \%$ of the mean. The distribution of each parameter (over many fitting runs) was plotted, so that central tendency could be judged by eye. For the majority of cells, it was judged that there was a reasonable central tendency, and error ranges were calculated in a nonparametric fashion by finding the parameter values which included $95 \%$ of the computed parameter values.

Current traces were filtered at $500 \mathrm{~Hz}$ before export from pClamp8 (Axon Instruments) to Photoshop 6.0 (Adobe) for preparation for the figures. Plots were prepared with Origin (Vers.6.1., Origin Lab Corp., Northhampton, MA). 
Statistical analysis was carried out by ANOVA followed by protected t-tests of specific cell pairs or DA-control pairs. Significant changes were accepted at $\mathrm{p}<0.05$; error bars in the figures represent the standard deviation (SD).

\section{Results}

\section{$I_{K(V)}$ consists of two components in pyloric neurons}

We performed two-electrode voltage clamp on the six different pyloric cell types to characterize their delayed rectifier-type potassium currents $\left(\mathrm{I}_{\mathrm{K}(\mathrm{V})}\right)$. The cells were held at $-40 \mathrm{mV}$ to inactivate $\mathrm{I}_{\mathrm{A}}$, while $\mathrm{I}_{\mathrm{Na}}$ was blocked with $0.1 \mu \mathrm{M}$ TTX, $\mathrm{I}_{\mathrm{Ca}}$ and $\mathrm{I}_{\mathrm{K}(\mathrm{Ca})}$ were blocked with $0.8 \mathrm{mM} \mathrm{CdCl}_{2}$, and $\mathrm{I}_{\mathrm{h}}$ was blocked with $5 \mathrm{mM} \mathrm{CsCl}$. All pyloric cell types expressed an $\mathrm{I}_{\mathrm{K}(\mathrm{V})}$ that consists of two current components with very different voltage activation ranges. In a majority of neurons among all cell types, this results in a g/V curve that has a marked bulge in the range of -10 to $+10 \mathrm{mV}$, followed by a rising increase in current at higher voltages (for example, Fig. 1E). However, even within a single cell type, there were marked differences in the relative proportions of the two current components. Based on their respective relative voltages of activation the two components were termed low voltage-activated (LVA) and high voltage-activated (HVA) $\mathrm{I}_{\mathrm{K}(\mathrm{V})}$.

Figure 1 shows three different pyloric dilator (PD) neurons, two cells (Figs. 1A and 1C) representing extreme current compositions and one cell (1B) representing the majority of cells. Figures 1D-F show the corresponding conductance/voltage plots. Figures 1A and D show a neuron possessing a majority of LVA current. In the current traces, the additional current at each step increases non-linearly up to the maximal activation, above which the additional voltage steps evoked currents that increased linearly with voltage due to the increased driving force on the current. The $\mathrm{g} / \mathrm{V}$ plot shows that this current approaches saturation at high voltages. Figures $1 \mathrm{~B}$ and $\mathrm{E}$ show the most typical results, with a mix of both LVA and HVA currents. The current increases and appears to saturate at intermediate voltages as in Fig. 1A, but then begins to increase a second time with higher voltage steps as the HVA component becomes activated. The resulting $\mathrm{g} / \mathrm{V}$ plot shows a marked bulge in the voltage range where the LVA component is saturating and the HVA 
component is just beginning to be expressed. Finally, Figures $1 \mathrm{C}$ and $\mathrm{F}$ show a PD neuron that has primarily the HVA component. Here, the current increases non-linearly with each voltage step throughout the voltage range that we could obtain, giving rise to the apparently exponential g/V relation seen in Fig. 1F. The majority of PD cells $(n=69)$ showed both currents in clearly visible, albeit variable amounts; only a minority showed primarily LVA $(n=6)$ or HVA $(n=13)$ currents.

Similar variability in the relative amounts of LVA and HVA components in $\mathrm{I}_{\mathrm{K}(\mathrm{V})}$ was seen in the other pyloric neurons. In the lateral pyloric (LP) neuron, 23 cells $(68 \%)$ showed a clear composite current, while 11 cells predominantly showed either the LVA $(\mathrm{n}=8)$ or the HVA $(\mathrm{n}=3)$ component. In Pyloric (PY), ventricular dilator (VD) and inferior cardiac (IC) neurons, 51\%, 73\%, and 54\% of the respective cell type showed the composite of two currents while the remaining cells split into equal numbers showing either current predominantly. Of the 10 anterior burster $(\mathrm{AB})$ cells measured, 9 showed both components and only one had no clear HVA component.

In order to separate these two currents, we fit the conductance/voltage relation with a formula that combines the Boltzmann function for the LVA component with an exponential function for the HVA component (see Materials and Methods). We believe that the second component is a normal saturable current which activates at depolarized levels but could in theory be fit by a Boltzmann relation. However, repeated attempts to fit the data as the sum of two Boltzmann components were unsuccessful; the HVA component is still rising quasi-exponentially at the highest voltages we could clamp the neuron, and these data were not adequate to constrain the fit by a Boltzmann function. Hence, to subtract out this current and allow a detailed study of the LVA component, we were forced to approximate it by an arbitrary exponential relation that does not yield any biophysically realistic parameters beyond measures of amplitude at different voltages. This formula gave a good fit to the majority of $\mathrm{g} / \mathrm{V}$ plots for all cell types, though the currents could not be adequately separated in many of our neurons. We subsequently separated the Boltzmann (LVA) and exponential (HVA) components using a mathematical program (Matlab, see Methods) (Fig. 2). The LVA component activates at 
voltages around $-25 \mathrm{mV}$ and saturates around $+20 \mathrm{mV}$ while the HVA component is very small at voltages below $0 \mathrm{mV}$ and does not begin to saturate at voltage steps up to $+45 \mathrm{mV}$. As a test for the accuracy of the Boltzmann fit of the LVA current, we subsequently refit the separated conductance/voltage relation to a single Boltzmann relation; its parameters did not differ significantly from the values for the LVA current obtained from the composite analysis of the combined currents. The mathematical separation also allowed us to determine the amplitude of the HVA component, but not its Boltzmann parameters. We chose to measure the fitted conductance at $+40 \mathrm{mV}$ where the current was well clamped in all cells and cell types, in order compare its amplitude among cell types and during dopamine application. The values for all the fitted parameters of the LVA as well as the conductance at $+40 \mathrm{mV}$ of the HVA are given in Table 1. Generally, the LP neuron has the biggest LVA conductance $(0.35 \pm 0.12 \mu \mathrm{S})$, with PD being second $(0.29 \pm 0.11 \mu \mathrm{S})$. The PY $(0.25 \pm 0.06 \mu \mathrm{S})$ and VD $(0.25 \pm 0.08 \mu \mathrm{S})$ neurons have similar but smaller amounts of this conductance, while the IC (0.21 \pm $0.08 \mu \mathrm{S})$ and $\mathrm{AB}(0.19 \pm 0.04 \mu \mathrm{S})$ neurons have the smallest amount among the pyloric neurons. The LVA values for LP are significantly greater than those for all other cells. LVA in the LP and PD neurons are also significantly larger than the two neurons with the smallest conductance (IC and $\mathrm{AB}$ ). The significance values were tested by one way analysis of variance, followed by protected t-tests of individual cell type pairs $(\mathrm{p}<0.05)$. The $\mathrm{V}_{1 / 2}$ of this current ranges from $-7.9 \mathrm{mV}$ in $\mathrm{AB}$ to $-12.3 \mathrm{mV}$ in $\mathrm{LP}$, while the slope value ranges from $-7.1 \mathrm{mV}$ in $\mathrm{PY}$ to $-10.2 \mathrm{mV}$ in $\mathrm{AB}$ cells. There is a large degree of overlap in the range of parameters between different neurons.

When measured at $+40 \mathrm{mV}$, the LP neuron has the largest HVA conductance $(0.29 \pm$ $0.27 \mu \mathrm{S})$, closely followed by the VD neuron $(0.27 \pm 0.16 \mu \mathrm{S})$. The PD and PY neurons have similar but smaller amounts $(0.20 \pm 0.15$ and $0.16 \pm 0.19 \mu \mathrm{S}$, respectively), while the IC and $\mathrm{AB}$ neurons have the smallest amount of HVA conductance $(0.11 \pm 0.05$ and 0.06 $\pm 0.03 \mu \mathrm{S}$, respectively). Thus, with the exception of the VD neuron, the pyloric neurons have the same rank order for both LVA and HVA currents. The ratio of LVA to HVA conductance varied depending on the cell type. It was highest in the $\mathrm{AB}$ neuron with a ratio of 3.2:1, due primarily to the very small HVA component in most of these neurons. 
The IC, PY and PD neurons had LVA:HVA ratios between 2:1 and 1.5:1 (Table 1). At the lower end of the spectrum were the LP and VD neurons with LVA to HVA ratios of 1.2:1 and $0.9: 1$, respectively.

Although we have referred to the LVA and HVA components as separate currents, it is formally possible that there is only a single current with LVA-like characteristics. In this case, the exponentially rising high-threshold component would appear as an artifact of poor space clamp of additional LVA current from distant, poorly clamped regions of the neuropil. We do not favor this interpretation for two major reasons. First, if this interpretation is true, it should hold for other currents as well. It is known that other currents, such as $\mathrm{I}_{\mathrm{A}}$ and $\mathrm{I}_{\mathrm{K}(\mathrm{Ca})}$, are distributed in the neuropil as well as the somata of pyloric neurons (for example, Baro et al. 2000), yet in previous voltage clamp studies of these currents, we have found their $\mathrm{g} / \mathrm{V}$ curves to show normal saturation with voltage (Baro et al. 1997, Kloppenburg et al. 1999). To test this directly, we measured $\mathrm{I}_{\mathrm{K}(\mathrm{Ca})}$ and $\mathrm{I}_{\mathrm{K}(\mathrm{V})}$ in the same neuron in a subset of 13 PD neurons. $\mathrm{I}_{\mathrm{K}(\mathrm{Ca})}$ was on average 4 times larger than $\mathrm{I}_{\mathrm{K}(\mathrm{V})}$ and its $\mathrm{g} / \mathrm{V}$ relation always approached saturation at higher voltage steps, with no evidence of a second exponential component. In contrast, in 12 out of the 13 PD neurons measured, the shape of the $\mathrm{g} / \mathrm{V}$ plot of $\mathrm{I}_{\mathrm{K}(\mathrm{V})}$ resembled that in figure $1 \mathrm{E}$ with its exponential rise at higher voltage steps (data not shown). Second, we performed a numerical analysis of a two compartment neuron model of the effects of currents in the distal neuropil. In this model, the soma compartment is voltage clamped and coupled to the neuropil compartment by a variable coupling conductance. Both compartments contain an LVA-type $\mathrm{I}_{\mathrm{K}(\mathrm{V})}$ with identical voltage dependence but variable maximal conductance. Since in voltage clamp, we measure the conductances at steady state, we can explicitly solve the differential equations for the apparent $\mathrm{I}_{\mathrm{K}(\mathrm{V})}$ measured in the soma, including any contribution from the neuropil compartment. We then calculated the contribution of the neuropil $\mathrm{I}_{\mathrm{K}(\mathrm{V})}$ to the $\mathrm{g} / \mathrm{V}$ curve measured in the soma over a wide range of coupling and conductance parameters, constrained only by the values of $\mathrm{V}_{1 / 2}$ and slope derived from our Boltzmann analysis of the LVA component. In all cases, the contribution of the neuropil current never behaves like a rising exponential function at voltages above $0 \mathrm{mV}$. Instead, it appears to be concave down in this voltage range, such 
that the composite current measured in the soma never has a bulge or second inflection point, as seen in the experimental observations. We carried out further analysis relaxing our constraints, and found that an exponentially rising HVA-like component could be obtained, but only with unrealistically small values of the slope parameter which are never seen in real ion channels. Details of this model are available on request.

\section{The two components of $\mathbf{I}_{K(V)}$ show partially different sensitivity to potassium channel blockers}

To compare the pharmacological profiles of the two currents, we studied their sensitivity to three known potassium channel blockers: tetraethylammonium (TEA), quinidine and 4-Aminopyridine (4-AP). In PD neurons, bath application of 5-100mM TEA reduces both components of the measured $\mathrm{I}_{\mathrm{K}(\mathrm{V})}$, down to about $10 \%$ of the initial value in a dose dependent manner.Figures $3 \mathrm{~A}$ and 3B show a PD neuron in control and in 50mM TEA. The $\mathrm{g} / \mathrm{V}$ plot in Fig. 3C shows the average normalized dose response to TEA for four PD neurons. The remaining current at each TEA concentration was digitally subtracted from the control current to determine the TEA-sensitive part of the conductance (Fig. 3D). This shows that both components are equally blocked at all concentrations of TEA used, as the bulge from the control graph is visible in all the TEA-sensitive conductance traces. Unfortunately, we were unable to clearly separate the LVA from the HVA components of the currents in these experiments, so a more quantitative analysis of the block of the two components was not possible.

We also tested whether other potassium channel blockers would differentially affect the two current components. Quinidine has been shown to differentially block two delayed rectifier type potassium currents in Drosophila larval muscles in a dose dependent manner (Singh and Singh 1999). The more sensitive of these two currents is encoded by the shab gene, while the second remains unidentified. We tested if the two delayed rectifier-type currents in the spiny lobster are also differentially affected by quinidine. We applied quinidine over a concentration range from $100 \mu \mathrm{M}$ to $1 \mathrm{mM}$. At equilibrium in $100 \mu \mathrm{M}$ quinidine, $35 \%$ of the total current was blocked. The block reaches $60 \%$ at $500 \mu \mathrm{M}$ quinidine, and in one case after application of $1 \mathrm{mM}$ quinidine up to $80 \%$ of $\mathrm{I}_{\mathrm{K}(\mathrm{V})}$ 
was blocked. Figure 4 shows an example of $\mathrm{I}_{\mathrm{K}(\mathrm{V})}$ in a PD cell and its block by application of $500 \mu \mathrm{M}$ quinidine (Fig. 4A,B). The concentration-dependent block of $\mathrm{I}_{\mathrm{K}(\mathrm{V})}$ averaged from three PD neurons and the respective $\mathrm{g} / \mathrm{V}$ plots are shown in figure $4 \mathrm{C}$. Analysis of the quinidine-sensitive current revealed that low concentrations of quinidine preferentially but only partially block the LVA current, with little detectable effect on the HVA current. This block is more complete at higher quinidine concentrations, but at concentrations above $500 \mu \mathrm{M}$, both LVA and HVA currents are reduced. Thus, the LVA and HVA currents show a different concentration-dependence of block by quinidine.

4-AP is a known blocker of the transient potassium current, $\mathrm{I}_{\mathrm{A}}$, but it also blocks two delayed rectifier-type currents in Drosophila (Singh and Singh 1999). We applied 4-AP in concentrations of 4,10 and $20 \mathrm{mM}$. With $4 \mathrm{mM}$ 4-AP the block of $\mathrm{I}_{\mathrm{K}(\mathrm{V})}$ rarely exceeded $25 \%$; even at $20 \mathrm{mM} 4$-AP, the total block never exceeded 50\%. Figure 5 shows an example of $\mathrm{I}_{\mathrm{K}(\mathrm{V})}$ in a PD cell and its block by application of $10 \mathrm{mM}$ 4-AP (Fig. 5A,B). The concentration dependence of 4-AP block averaged from five PD neurons is shown in Fig.5C, and the 4-AP-sensitive current is shown in Fig. 5D. At the lowest concentration used, 4mM, 4-AP clearly differentially blocks the LVA current component more than the HVA component; the 4-AP-sensitive current predominantly saturates at +10 to $+20 \mathrm{mV}$, as the isolated LVA component does. However, at higher concentrations, the HVA component is partially blocked as well (Fig. 5D). Thus, the HVA and LVA currents also show a different dose-dependence of block by 4-AP.

We also performed double blocker experiments, testing the effect of sequential application of 4-AP or quinidine with TEA, or TEA with 4-AP or quinidine. The partial block of $\mathrm{I}_{\mathrm{K}(\mathrm{V})}$ by either 4-AP or quinidine alone could always be enhanced by the application of TEA, demonstrating that quinidine and 4-AP fail to block all $\mathrm{I}_{\mathrm{K}(\mathrm{V})}$. On the other hand, the TEA block was more complete and occluded any additional block by 4AP or quinidine. In an experiment where we sequentially applied 4-AP and quinidine, currents not blocked by 4-AP could be further reduced by quinidine, whereas currents not blocked by quinidine could not further be reduced by 4AP (data not shown). These experiments demonstrate that TEA is the most non-specific of the $\mathrm{K}^{+}$channel blockers 
tested on the LVA and HVA currents. Low concentrations of quinidine and 4-AP selectively block the LVA component, but quinidine appears to be less specific than 4AP, blocking a significant amount of he HVA current at the highest concentrations. Although we were unable to separate the blocked currents mathematically due to poor fits of the respective $\mathrm{g} / \mathrm{V}$ plots in the presence of blockers, these results argue further that the LVA and HVA components are independent potassium currents and not the result of poor space clamp of a single distributed current.

\section{Dopamine modulates $\mathbf{I}_{\mathbf{K}(\mathrm{V})}$ in selected pyloric neurons}

Dopamine (DA) has a profound effect on the firing pattern of the actively cycling pyloric network. DA excites the AB, LP, PY and IC neurons, increasing their maximal spike frequency during their bursts, while inhibiting the PD and VD neurons (Flamm and Harris-Warrick 1986a,b). To see whether modification of $I_{K(V)}$ could contribute to these effects, we tested the effect of $0.1 \mathrm{mM}$ DA on $\mathrm{I}_{\mathrm{K}(\mathrm{V})}$ in all pyloric cell types. DA had no effect on $I_{K(V)}$ in the PD neuron, as previously reported (Kloppenburg et al. 1999) $(n=4)$. DA also did not significantly affect $\mathrm{I}_{\mathrm{K}(\mathrm{V})}$ in the LP, VD and IC neurons (data not shown, $\mathrm{n}=6,5$ and 3 , respectively).

However, the major pyloric pacemaker neuron, the AB interneuron, showed a reversible increase in steady-state $\mathrm{I}_{\mathrm{K}(\mathrm{V})}$ of up to $40 \%$ (average $22 \pm 18 \%, \mathrm{n}=4$ ) in the presence of DA. Figures 6A-C show the current traces under control conditions, after a 5min. application of $0.1 \mathrm{mM}$ DA and during wash after DA. The g/V plot in Fig 6D shows that the effect is noticeable at $-15 \mathrm{mV}$, and becomes statistically significant at voltage steps above $+5 \mathrm{mV}$. The mathematical separation of the two currents in the four cells measured was unsuccessful in these cases, due to the small size of the HVA component, which could not be reliably fit. Nonetheless, it appears that both components are enhanced by DA.

A majority of the PY neurons also showed a significant and reversible increase in steady state $\mathrm{I}_{\mathrm{K}(\mathrm{V})}$ during DA application. There are 8 PY neurons in P. interruptus, which show varying excitatory responses to DA (Johnson et al. 2004). DA was applied to 9 PY cells that showed a clear bulge under control conditions. Figure 7A-C shows sample current 
traces from a typical experiment, while the normalized $\mathrm{g} / \mathrm{V}$ plot of the averaged DA effect from all 9 PY cells is given in Fig. 7D. The DA enhancement becomes significant above $0 \mathrm{mV}$. While there was variability in strength of the DA effect, eight out of nine PY neurons showed a DA-dependent reversible increase in steady-state total $\mathrm{I}_{\mathrm{K}(\mathrm{V})}$ of between $17 \%$ and $38 \%$ (average $29 \pm 8 \%, n=8$ ); one PY neuron showed no effect (Fig.7E).

We were able to separate the PY neuron composite currents into their LVA and the HVA components. This analysis demonstrated that DA increases the conductance of both components (Fig. 8A, B). The $\mathrm{LVA}_{(\max )}$ is increased by $26 \% \pm 35 \%$. Boltzmann analysis of the LVA component revealed that the DA effect was limited to the maximal conductance: the $\mathrm{V}_{1 / 2}$ and the slope parameters of this component were not affected by DA in PY neurons (Table 2). The HVA conductance at $+40 \mathrm{mV}$ was also enhanced, by $330 \pm 480 \%$; however, this very large increase is predominantly due to a very large effect in one neuron that had a very small initial HVA current, with most neurons showing less than $100 \%$ increase (Fig. 8D). The increase in the LVA component is significant above $-5 \mathrm{mV}$, while the increase in the HVA current is significant above $+10 \mathrm{mV}$. The enhancement of the LVA component washes out more poorly than the HVA component. When comparing DA actions on the PY neurons, it is clear that there is a continuum of responses among PY neurons. In two cells either the LVA or the HVA component actually decreased during DA, despite a net increase in total $\mathrm{I}_{\mathrm{K}(\mathrm{V})}$ conductance in those cells (Fig. 8C,D). 


\section{Discussion}

\section{$I_{K(V)}$ is composed of two components}

After blocking $\mathrm{I}_{\mathrm{Na}}, \mathrm{I}_{\mathrm{Ca}}, \mathrm{I}_{\mathrm{K}(\mathrm{Ca})}$ and $\mathrm{I}_{\mathrm{h}}$ and inactivating most of the transient potassium current $\mathrm{I}_{\mathrm{A}}$, we found that the majority of pyloric neurons express an $\mathrm{I}_{\mathrm{K}(\mathrm{V})}$ that appears to be made up of at least two components, resulting in a $\mathrm{g} / \mathrm{V}$ curve with a pronounced bulge in the range of -10 to $+10 \mathrm{mV}$. The first, low voltage-activated component (LVA) activates at voltage steps above $-25 \mathrm{mV}$, while the second, high voltage-activated component (HVA) is small below $0 \mathrm{mV}$ and does not saturate at voltage steps up to $+45 \mathrm{mV}$. These two components are both blocked by TEA, and are clearly $\mathrm{K}^{+}$currents. The finding that $\mathrm{I}_{\mathrm{K}(\mathrm{V})}$ is made up of two separate currents is in accord with reports from several vertebrate and invertebrate systems, where multiple delayed rectifier-type potassium currents coexist in one cell type (Covarrubias et al. 1991; Martinez-Padron and Ferrus 1997; Baranauskas et al. 1999; Singh and Singh 1999; Rothman and Manis 2003).

We were able to fit the $g / V$ relationship for the pyloric $\mathrm{I}_{\mathrm{K}(\mathrm{V})}$ with a formula that combined a Boltzmann relation for the saturable LVA component with an exponential equation for the HVA current that approximates the initial quasi-exponential rise of a second Boltzmann component. We were unable to fit the second component with a Boltzmann relation, as the current did not begin to saturate at the highest voltage we could hold, $+45 \mathrm{mV}$. These fits were then mathematically separated to generate the $\mathrm{g} / \mathrm{V}$ plots of the individual LVA and HVA components. The LVA component was usually well fit by the Boltzmann relation. However, in neurons with small amounts of HVA current, the error in fitting the HVA component could be large. Therefore, in such neurons, the values for the separated HVA component need to be interpreted with caution. Since we could not fit the HVA component with a Boltzmann relation, the only parameter we could determine is an estimate of its amplitude at a particular voltage, which we set at $+40 \mathrm{mV}$.

The $\mathrm{V}_{1 / 2}$ and slope values of the Boltzmann parameters for the LVA current varied little between cell types. This indicates that the LVA current has similar properties in all the 
pyloric neurons. However, the maximal conductance $\left(\mathrm{g}_{(\max )}\right)$ of the LVA current and the conductance of the HVA component at $+40 \mathrm{mV}$ varied significantly between the cell types. The LP, PD and PY neurons generally had the largest, and IC and AB had the smallest amounts of both the LVA and the HVA components. The VD neuron did not follow this pattern: it showed the third smallest LVA $\mathrm{g}_{(\max )}$, but the second biggest HVA $g_{(+40)}$. These results indicate a cell type-dependent differential expression of the two $I_{K(V)}$ currents. A similar finding has been reported for $\mathrm{I}_{\mathrm{A}}$ in the lobster (Baro et al. 1997; Baro and Harris-Warrick 1998).

There remains another potential explanation for the presence of the HVA component. The high-threshold current could be an artifact as a result of poor space clamp and the apparently exponential recruitment of the same LVA current located in distant, poorly clamped regions of the neuropil. With our current data, we are unable to completely exclude this possibility. Several arguments, however, make this an unlikely explanation. First, we have performed a numerical analysis of a two compartment neuron model, where the soma compartment is voltage clamped and coupled to the neuropil compartment by a variable coupling conductance. In all cases where realistic parameters for $\mathrm{V}_{1 / 2}$ and slope were used, the contribution of the neuropil current appears to be concave down for voltages above $0 \mathrm{mV}$, and thus does not resemble the experimental result with its convex up shape that appears at higher voltages. Second, both LVA and HVA currents are blocked equally by TEA at all concentrations, whereas at low concentrations, both 4-AP and quinidine preferentially block the LVA component, with little effect on the HVA component (Figures 3-5). Third, neither $I_{K(C a)}$ nor $I_{A}$ in the pyloric neurons shows a g/V curve with an exponential component at high voltages; these currents can be well fitted with a single Boltzmann relation (Harris-Warrick et al. 1995; Baro et al. 1997; Kloppenburg et al. 1999). We measured $\mathrm{I}_{\mathrm{K}(\mathrm{Ca})}$ in a number of cells that were subsequently used for $\mathrm{I}_{\mathrm{K}(\mathrm{V})}$ measurements (Gruhn, unpublished observations); in all cases, $\mathrm{I}_{\mathrm{K}(\mathrm{Ca})}$ was a typical saturating current while in nearly all the neurons $\mathrm{I}_{\mathrm{K}(\mathrm{V})}$ showed its exponential HVA component at high voltages. Although, these arguments are not completely conclusive, they strongly suggest that there are two separate components of $\mathrm{I}_{\mathrm{K}(\mathrm{V})}$ in these neurons. 


\section{Possible molecular basis for multiple $\mathbf{I}_{\mathrm{K}(\mathrm{V})}$ components in pyloric neurons}

In Drosophila melanogaster, $\mathrm{I}_{\mathrm{K}(\mathrm{V})}$ is primarily encoded by the shab and shaw potassium channel genes (Covarrubias et al. 1991; Tsunoda and Salkoff 1995a,b). All the pyloric neurons express the lobster homologues of shab and shaw (Baro et al. 1996a; French et al. 2004). In many species, Shab/Kv2 channels are activated at lower threshold voltages $(-40$ to $-20 \mathrm{mV})$ than Shaw/Kv3 channels (threshold between $-30 \mathrm{mV}$ and $0 \mathrm{mV}$; Pak et al. 1991; Elkes et al. 1997; Johnstone et al. 1997; Ono et al. 1999; Panofen et al. 2000; Rashid et al. 2001; Rudy and McBain 2001; Wicher et al. 2001). Furthermore, Kv3/Shaw currents often do not saturate at voltages below $+80 \mathrm{mV}$ (Johnstone et al. 1997; Panofen et al. 2000). This raises the possibility that the LVA and the HVA components of $I_{K(V)}$ in Panulirus could be encoded by the lobster shab and shaw homologues, respectively.

Unfortunately, the pharmacological evidence is less clear. Quinidine is a fairly selective Shab antagonist at $100 \mu \mathrm{M}$ in Drosophila larval muscle, where it blocks $89 \%$ of Shab and $\sim 35 \%$ of an as yet unidentified additional delayed rectifier-type $\mathrm{K}$-current $\left(\mathrm{K}_{\mathrm{F}}\right)(\mathrm{Singh}$ and Singh 1999). This resembles the relatively selective block of the LVA current at low concentrations in pyloric neurons (Fig. 4). However, 4-AP also selectively blocked the LVA component at low concentrations in our pyloric neurons (Fig. 5), whereas in the Drosophila larval preparation, $5 \mathrm{mM} 4$-AP blocks the Shab current and the unidentified $\mathrm{K}_{\mathrm{F}}$-current equally (Singh and Singh 1999). In Xenopus oocytes, 4-AP is a much more selective antagonist of Drosophila Shaw than Shab (Tsunoda and Salkoff 1995; Wicher et al. 2001). Thus, at present the LVA and HVA components of $I_{K(V)}$ in the lobster cannot be readily assigned to specific genes, though we suggest that the LVA component may be a Shab current and the HVA component a Shaw current. Further experiments will be needed to confirm this hypothesis.

\section{Dopamine enhances $I_{K(V)}$ in a subset of pyloric neurons}

Dopamine affects the pyloric network by increasing the firing frequency of some neurons while reducing it in others (Flamm and Harris-Warrick 1986a,b). The observed changes 
are in part due to modulatory effects on $\mathrm{I}_{\mathrm{A}}, \mathrm{I}_{\mathrm{K}(\mathrm{Ca})}, \mathrm{I}_{\mathrm{h}}$ and $\mathrm{I}_{\mathrm{Ca}}$ in the different neurons (Harris-Warrick et al. 1995a, b; Kloppenburg et al. 1999; Peck et al. 2001; Johnson et al. 2003). We found that DA reversibly increased the total $I_{K(V)}$ conductance in the $A B$ neuron and in a subset of the 8 PY neurons by $22 \%$ and $29 \%$, respectively. Although we were unable to mathematically separate the LVA and HVA components in the $\mathrm{AB}$ neuron, the DA-induced increase becomes significant at voltages where the LVA component is activated and the HVA component is still very small, and continues above the range where the LVA component is saturated. This suggests that both components are enhanced by $\mathrm{DA}$ in the $\mathrm{AB}$ neuron. We were able to separate the LVA and HVA components in the PY neurons, and showed a significant DA-induced increase in the conductance of both components. DA appears to elicit a continuous spectrum of effects in the PY neurons investigated, from strong enhancement of $\mathrm{I}_{\mathrm{K}(\mathrm{V})}$ to very weak reduction in this current (Fig. 7E). Similar continuous variability in DA modulation of the firing properties among the 8 PY neurons has been observed (B. Johnson et al., unpublished observations), arguing that the 8 PY neurons are not easily subdivided into two subpopulations (Hartline et al. 1987).

The relationship between the DA-induced increase in $\mathrm{I}_{\mathrm{K}(\mathrm{V})}$ in the $\mathrm{AB}$ and PY neurons and the previously observed DA-evoked increase in firing frequency in these cells (Flamm and Harris-Warrick 1986a,b; Harris-Warrick et al. 1998) remains unclear. Since the $\mathrm{I}_{\mathrm{K}(\mathrm{V})}$ components, and in particular the HVA component, are only activated at suprathreshold voltages, they most likely play roles in determining the repolarization of action potentials, and the spike frequency during bursts. The HVA component will only be partially activated in the physiological voltage range; in this it is similar to $\mathrm{I}_{\mathrm{h}}$, whose full activation requires hyperpolarization well below $-100 \mathrm{mV}$. In cortical inhibitory neurons and auditory neurons, Kv3.1 channels show extremely rapid activation and deactivation (Rudy et al. 1999; Rudy and McBain 2001; Macica et al. 2003). Increases in these currents accelerate peak spike frequency by facilitating rapid repolarization of the action potential, thus reducing inactivation of sodium channels and decreasing the minimal interval between spikes. In the pyloric neurons, however, the kinetics of $\mathrm{I}_{\mathrm{K}(\mathrm{V})}$ activation and deactivation are much slower, and do not act rapidly enough to increase maximal 
spike frequency. Modeling of the role of $\mathrm{I}_{\mathrm{K}(\mathrm{V})}$ in PY neurons (Harris-Warrick et al. 1995b) suggested that increasing this current would decrease spike frequency due to its slow deactivation rate. In addition, increasing $\mathrm{I}_{\mathrm{K}(\mathrm{V})}$ in oscillating $\mathrm{AB}$ neuron models does not accelerate spike frequency and modestly slows the period of the $\mathrm{AB}$ oscillations (Guckenheimer et al. 1992 and unpublished observations). Thus, it is possible that the DA-evoked increases in $\mathrm{I}_{\mathrm{K}(\mathrm{V})}$ actually oppose the increase in spike frequency in $\mathrm{AB}$ and PY neurons caused by the other modulatory effects of DA on $\mathrm{I}_{\mathrm{A}}, \mathrm{I}_{\mathrm{Ca}}$, and $\mathrm{I}_{\mathrm{h}}$ (HarrisWarrick et al. 1995a,b; Peck et al. 2001; Johnson et al. 2003; Peck et al., unpublished observations). These opposing actions would act in concert to constrain the DA-induced increase in excitability to within certain bounds. This in turn would increase the reliability of the DA effect, and reduce the risk that the preparation will become "overmodulated" and dysfunctional.

One way to directly determine the function of $\mathrm{I}_{\mathrm{K}(\mathrm{V})}$ and assess the influence of the DA modulatory effect on $\mathrm{I}_{\mathrm{K}(\mathrm{V})}$ in $\mathrm{PY}$ and $\mathrm{AB}$ neurons would be to selectively block the current and look for changes in firing and DA responsiveness. However, at present, there are no specific blockers for $\mathrm{I}_{\mathrm{K}(\mathrm{V})}$, or its LVA or HVA components, in lobster neurons. 4AP and quinidine also reduce $\mathrm{I}_{\mathrm{A}}$ (Graubard and Hartline 1991; Tierney and HarrisWarrick 1992, and M.Gruhn, unpublished observations), while TEA also blocks $\mathrm{I}_{\mathrm{K}(\mathrm{Ca})}$ (Kloppenburg et al. 1999). Since DA also affects $I_{A}, I_{h}$ and $I_{C a}$ in PY and AB neurons (Peck et al. 2001; Johnson et al. 2003; J. Peck et al. unpublished observations), the DAevoked changes in activity result from a complex interaction of DA's effects on all these currents.

Acknowledgements: We thank Drs. Bruce Johnson and Jack Peck, as well as Marie Goeritz for valuable comments and discussions. Thanks to Dr Peck also for help with the statistical analysis. This work was supported by NIH grant NS 17323 to RMH-W. 


\section{Literature Cited}

Armstrong, C.M. and Bezanilla, F. Charge movement associated with the opening and closing of the activation gates of the Na channels. J Gen Physiol, 63, 533-552, 1974.

Ayali, A., Johnson, B.R. and Harris-Warrick, R.M. Dopamine modulates graded and spike-evoked synaptic inhibition independently at single synapses in pyloric network of lobster. J. Neurophysiol., 79, 2063-2069, 1998.

Ayali, A. and Harris-Warrick, R.M. Monoamine control of the pacemaker kernel and cycle frequency in the lobster pyloric network. J. Neurosci, 19, 6712-6722, 1999.

Baranauskas, G., Tkatch, T. and Surmeier, D.J. Delayed rectifier currents in rat globus pallidus neurons are attributable to Kv2.1 and Kv3.1/3.2 $\mathrm{K}^{+}$channels. $J$ Neurosci, 19, 6394-6404, 1999.

Baro, D.J., Cole, C.L. and Harris-Warrick, R.M. RT-PCR analysis of shaker, shab, shaw, and shal gene expression in single neurons and glial cells. Receptors. Channels., 4, 149-159, 1996 .

Baro, D.J., Coniglio, L.M., Cole, C.L., Rodriguez, H.E., Lubell, J.K., Kim, M.T. and Harris-Warrick, R.M. Lobster shal: comparison with Drosophila shal and native potassium currents in identified neurons. J. Neurosci, 16, 1689-1701, 1996b.

Baro, D.J., Levini, R.M., Kim, M.T., Willms, A.R., Lanning, C.C., Rodriguez, H.E. and Harris-Warrick, R.M. Quantitative single-cell-reverse transcription-PCR demonstrates that A-current magnitude varies as a linear function of shal gene expression in identified stomatogastric neurons. J. Neurosci., 17, 6597-6610, 1997.

Baro, D.J. and Harris-Warrick, R.M. Differential expression and targeting of $\mathrm{K}^{+}$ channel genes in the lobster pyloric central pattern generator. Ann. N.Y. Acad. Sci., 860:281-95, 281-295, 1998.

Baro, D.J., Ayali, A., French, L., Scholz, N.L., Labenia, J., Lanning, C.C., Graubard, K. and Harris-Warrick, R.M. Molecular underpinnings of motor pattern generation: differential targeting of shal and shaker in the pyloric motor system. J Neurosci, 20, 6619-6630, 2000.

Calabrese, R.L. Neuronal networks: dissection one channel at a time. Curr Biol, 14, R154-155, 2004.

Coetzee, W.A., Amarillo, Y., Chiu, J., Chow, A., Lau, D., McCormack, T.O.M., Morena, H., Nadal, M.S., Ozaita, A., Pountney, D., Saganich, M., De Miera, E.V.-S. and Rudy, B. Molecular Diversity of K+ Channels. Ann. N.Y. Acad. Sci., 868, 233, 1999.

Covarrubias, M., Wei, A.A. and Salkoff, L. Shaker, Shal, Shab, and Shaw express independent $\mathrm{K}^{+}$current systems. Neuron, 7, 763-773, 1991.

Dodson, P.D. and Forsythe, I.D. Presynaptic $\mathrm{K}^{+}$channels: electrifying regulators of synaptic terminal excitability. TINS, 27, 210-217, 2004.

Elkes, D.A., Cardozo, D.L., Madison, J. and Kaplan, J.M. EGL-36 Shaw channels regulate $C$. elegans egg-laying muscle activity. Neuron, 19, 165-174, 1997. 
Flamm, R.E. and Harris-Warrick, R.M. Aminergic modulation in lobster stomatogastric ganglion. I. Effects on motor pattern and activity of neurons within the pyloric circuit. J Neurophysiol, 55, 847-865, 1986a.

Flamm, R.E. and Harris-Warrick, R.M. Aminergic modulation in lobster stomatogastric ganglion. II. Target neurons of dopamine, octopamine, and serotonin within the pyloric circuit. J Neurophysiol, 55, 866-881, 1986 b.

French, L.B., Lanning, C.C., Matly, M. and Harris-Warrick, R.M. Cellular localization of Shab and Shaw potassium channels in the lobster stomatogastric ganglion. Neuroscience, 123, 919-930, 2004.

Golowasch, J., Buchholtz, F., Epstein, I.R. and Marder, E. Contribution of individual ionic currents to activity of a model stomatogastric ganglion neuron. $J$. Neurophysiol., 67, 341-349, 1992.

Golowasch, J. and Marder, E. Ionic currents of the lateral pyloric neuron of the stomatogastric ganglion of the crab. J. Neurophysiol., 67, 318-331, 1992.

Graubard, K. and Hartline, D.K. Voltage clamp analysis of intact stomatogastric neurons. Brain Res, 557, 241-254, 1991.

Gruhn, M. and Harris-Warrick, R.M. Characterization of delayed rectifier-type potassium currents in cells in the pyloric circuit of the stomatogastric ganglion in the spiny lobster Annual Meeting of the Society for Neuroscience, New Orleans, LA, 2003.

Gruhn, M., Guckenheimer, J., Land, B. and Harris-Warrick, R.M. Dopamine modulation of delayed rectifier-type potassium currents in the pyloric circuit of the lobster stomatogastric ganglion Annual Meeting of the Society for Neuroscience, San Diego, CA, 2004.

Harris-Warrick, R., Marder, E., Selverston, A. and Moulins, M. Dynamic biological networks: the stomatogastric nervous system. MIT Press, Cambridge, MA, 1992.

Harris-Warrick, R.M., Coniglio, L.M., Barazangi, N., Guckenheimer, J. and Gueron, S. Dopamine modulation of transient potassium current evokes phase shifts in a central pattern generator network. J. Neurosci, 15, 342-358, 1995a.

Harris-Warrick, R.M., Coniglio, L.M., Levini, R.M., Gueron, S. and Guckenheimer, J. Dopamine modulation of two subthreshold currents produces phase shifts in activity of an identified motoneuron. J. Neurophysiol., 74, 1404-1420, 1995 b.

Harris-Warrick, R.M., Johnson, B.R., Peck, J.H., Kloppenburg, P., Ayali, A. and Skarbinski, J. Distributed effects of dopamine modulation in the crustacean pyloric network. Ann. N.Y. Acad. Sci., 860, 155-167, 1998.

Harris-Warrick, R.M. Voltage-sensitive ion channels in rhythmic motor systems. Curr Opin Neurobiol, 12, 646-651, 2002.

Hartline, D.K. Pattern generation in the lobster (Panulirus) stomatogastric ganglion. II. Pyloric network simulation. Biol Cybern, 33, 223-236, 1979.

Hartline, D.K.,Gassie D.V., Sirchia C.D. PY cell types in the stomatogastric ganglion of Panulirus. in: Selverston A.I. and Moulins M. (eds.) The Crustacean Stomatogastric System. Springer-Verlag, Berlin, pp.75-77, 1987.

Hartline, D.K. and Graubard, K. Cellular and synaptic properties in the stomatogastric nervous system. In Harris-Warrick, R.M., Marder, E., Selverston, A.I., Moulins, M. (eds.) Dynamic biological networks: The stomatogastric nervous system. MITPress, Cambrige, MA, pp. 1-30, 1992. 
Johnson, B.R. and Harris-Warrick, R.M. Aminergic modulation of graded synaptic transmission in the lobster stomatogastric ganglion. J Neurosci., 10, 2066-2076, 1990.

Johnson, B.R., Peck, J.H. and Harris-Warrick, R.M. Distributed amine modulation of graded chemical transmission in the pyloric network of the lobster stomatogastric ganglion. J. Neurophysiol., 74, 437-452, 1995.

Johnson, B.R., Kloppenburg, P. and Harris-Warrick, R.M. Dopamine modulation of calcium currents in pyloric neurons of the lobster stomatogastric ganglion. $J$. Neurophysiol., 90, 631-643, 2003.

Johnson, B.R., Nadim, F., Schneider, L. and Harris-Warrick, R.M. Dopamine modifies firing phase in a rhythmic network through synaptic sign reversal and activation of silent synapses Annual Meeting of the Society for Neuroscience, San Diego, CA, 2004.

Johnstone, D.B., Wei, A., Butler, A., Salkoff, L., and Thomas J.H. Behavioral defects in C. elegans egl-36 mutants result from potassium channels shifted in voltagedependence of activation. Neuron. 19(1):151-64, 1997.

Kim, M., Baro, D.J., Lanning, C.C., Doshi, M., Farnham, J., Moskowitz, H.S., Peck, J.H., Olivera, B.M. and Harris-Warrick, R.M. Alternative splicing in the poreforming region of shaker potassium channels. J. Neurosci., 17, 8213-8224, 1997.

Kim, M., Baro, D.J., Lanning, C.C., Doshi, M., Moskowitz, H.S., Farnham, J. and Harris-Warrick, R.M. Expression of Panulirus shaker potassium channel splice variants. Receptors. Channels., 5, 291-304, 1998.

Kloppenburg, P., Levini, R.M. and Harris-Warrick, R.M. Dopamine modulates two potassium currents and inhibits the intrinsic firing properties of an identified motor neuron in a central pattern generator network. J. Neurophysiol., 81, 29-38, 1999.

Macica, C.M.,von Hehn, C.A.A., Wang, L.-Y., Ho, C.-S., Yokoyama, S., Joho, R.H., Kaczmarek, L.K. Modulation of the Kv3.1b potassium channel isoform adjusts the fidelity of the firing pattern of auditory neurons. J. Neurosci, 23, 1133-1141, 2003.

Marder, E. and Thirumalai, V. Cellular, synaptic and network effects of neuromodulation. Neural Networks, 15, 479, 2003.

Martinez-Padron, M. and Ferrus, A. Presynaptic recordings from Drosophila: correlation of macroscopic and single-channel $\mathrm{K}^{+}$currents. J. Neurosci, 17, 34123424, 1997.

Mulloney, B. and Selverston, A.I. Organization of the stomatogastric ganglion of the spiny lobster.III.Coordination of the two subsets of the gastric system. J. Comp. Physiol., 91, 53-78, 1974.

Ono, F., Katsuyama, Y., Nakajo, K. and Okamura, Y. Subfamily-specific posttranscriptional mechanism underlies $\mathrm{K}^{+}$channel expression in a developing neuronal blastomere. J. Neurosci., 19, 6874-6886, 1999.

Ozaita, A., Petit-Jacques, J., Volgyi, B., Ho, C.S., Joho, R.H., Bloomfield, S.A. and Rudy, B. A unique role for Kv3 voltage-gated potassium channels in starburst amacrine cell signaling in mouse retina. J. Neurosci., 24, 7335-7343, 2004. 
Pak, M.D., Covarrubias, M., Ratcliffe, A. and Salkoff, L. A mouse brain homolog of the Drosophila Shab $\mathrm{K}^{+}$channel with conserved delayed-rectifier properties. $J$. Neurosci., 11, 869-880, 1991.

Pal, S., Hartnett, K.A., Nerbonne, J.M., Levitan, E.S. and Aizenman, E. Mediation of neuronal apoptosis by Kv2.1-encoded potassium channels. J. Neurosci., 23, 47984802, 2003.

Panofen, F., Rabe, H., Henne, J. and Jeserich, G. Molecular cloning and functional characterization of Shaw-related potassium channels of trout CNS. Brain Res. Mol. Brain Res., 83, 9-19, 2000.

Peck, J.H., Nakanishi, S.T., Yaple, R. and Harris-Warrick, R.M. Amine modulation of the transient potassium current in identified cells of the lobster stomatogastric ganglion. J. Neurophysiol., 86, 2957-2965, 2001.

Peck, J.H., Repicky, S. and Harris-Warrick, R.M. The effect of blocking the hyperpolarization-activated inward current $\left(\mathrm{I}_{\mathrm{h}}\right)$ on the pyloric motor rhythm of the stoatogastric ganglion (STG) of the lobster, Panulirus interruptus Annual Meeting of the Society for Neuroscience, San Diego, CA, 2004.

Rashid, A.J., Morales, E., Turner, R.W. and Dunn, R.J. The contribution of dendritic $\mathrm{Kv} 3 \mathrm{~K}^{+}$channels to burst threshold in a sensory neuron. J. Neurosci, 21, 125-135, 2001.

Rothman, J.S. and Manis, P.B. Differential expression of three distinct potassium currents in the ventral cochlear nucleus. J. Neurophysiol., 89, 3070-3082, 2003.

Rudy, B. and McBain, C.J. Kv3 channels: voltage-gated $\mathrm{K}^{+}$channels designed for highfrequency repetitive firing. Trends Neurosci, 24, 517-526, 2001.

Salkoff, L., Baker, K., Butler, A., Covarrubias, M., Pak, M.D. and Wei, A. An essential 'set' of $\mathrm{K}^{+}$channels conserved in flies, mice and humans.Trends Neurosci. May;15(5):161-6, 1992

Selverston, A.I., Russel, D.F., Miller, J.P. and King, D.G. The stomatogastric nervous system: structure and function of a small neural network. Progr. Neurobiol. 7:215-290, 1976

Shevchenko, T., Ryoichi, T. and Armstrong, W.E. High threshold, Kv3-like potassium currents in magnocellular neurosecretory neurons and their role in spike repolarization. J. Neurophysiol., 92, 3043-3053, 2004.

Singh, A. and Singh, S. Unmasking of a novel potassium current in Drosophila by a mutation and drugs. J. Neurosci., 19, 6838-6843, 1999.

Tierney, A.J. and Harris-Warrick, R.M. Physiological role of the transient potassium current in the pyloric circuit of the lobster stomatogastric ganglion. $J$. Neurophysiol., 67, 599-609, 1992.

Tsunoda, S. and Salkoff, L. Genetic analysis of Drosophila neurons: Shal, Shaw, and Shab encode most embryonic potassium currents. J. Neurosci., 15, 1741-1754, 1995a.

Tsunoda, S. and Salkoff, L. The major delayed rectifier in both Drosophila neurons and muscle is encoded by Shab. J. Neurosci., 15, 5209-5221, 1995b.

Wicher, D., Walther, C. and Wicher, C. Non-synaptic ion channels in insects--basic properties of currents and their modulation in neurons and skeletal muscles. Prog. Neurobiol., 64, 431-525, 2001. 


\section{Figure legends}

\section{Figure 1:}

Current and voltage traces showing variability of $\mathrm{I}_{\mathrm{K}(\mathrm{V})}$ in three different pyloric dilator (PD) neurons. Currents (A-C) were measured during 500ms voltage steps from a holding potential of $-40 \mathrm{mV}$ to between -30 and $+40 \mathrm{mV}$ in $5 \mathrm{mV}$ steps. D-F show the corresponding conductance/voltage plots. A and D. A PD possessing a majority of LVA current; the $\mathrm{g} / \mathrm{V}$ plot shows that this current approaches saturation at high voltages. $\mathrm{B}$ and E. A mix of both LVA and HVA currents. The resulting $\mathrm{g} / \mathrm{V}$ plot (E) shows a marked bulge in the voltage range where the LVA component is saturating and the HVA component is just beginning to be expressed. $\mathrm{C}$ and $\mathrm{F}$. A PD neuron that has primarily the HVA component. Here, the current steps increase continuously with voltage throughout the voltage range that we could obtain, giving rise to an apparently exponential $\mathrm{g} / \mathrm{V}$ relation $(\mathrm{F})$.

\section{Figure 2:}

Separation of $\mathrm{I}_{\mathrm{K}(\mathrm{V})}$ into LVA and HVA components A: Average $\mathrm{g} / \mathrm{V}$ plot of $\mathrm{I}_{\mathrm{K}(\mathrm{V})}$ in $69 \mathrm{PD}$ neurons after superperfusing the ganglion with Panulirus saline containing $5 \mathrm{mM} \mathrm{CsCl}$, $0.1 \mu \mathrm{M}$ TTX, $5 \mu \mathrm{M}$ PTX, and $0.8 \mathrm{mM} \mathrm{CdCl}_{2}$ for a minimum of $30 \mathrm{~min}$. Note the clear bulge around $10 \mathrm{mV}$. B. Average total conductance from A (a) and mathematically separated low voltage activated (LVA, •) and high voltage activated (HVA, $\mathbf{\Delta}$ ) components. Error bars mark SD.

\section{Figure 3:}

TEA blocks $\mathrm{I}_{\mathrm{K}(\mathrm{V})}$. Current traces of $\mathrm{I}_{\mathrm{K}(\mathrm{V})}$ under control conditions (A) and after perfusion with 50mM TEA (B). Measurements made as in Fig. 2. C. Normalized g/V relationship of the total conductance in 4 PD neurons under control conditions ( $\boldsymbol{a})$ and after equilibrating with 5mM TEA $(\bullet), 20 \mathrm{mM}$ TEA $(\boldsymbol{\Delta})$, and 50mM TEA ( $\boldsymbol{\nabla})$. D. Normalized $\mathrm{g} / \mathrm{V}$ relationship of TEA-sensitive conductance after equilibration with $5 \mathrm{mM}$ TEA ( $\boldsymbol{\square})$, 20mM TEA $(\bullet)$, and 50mM TEA $(\boldsymbol{\Delta})$. These were calculated by digital subtraction of TEA-blocked currents from control values and normalized against the maximum control conductance for each cell. Note that the shape closely follows that of the control conductance $(\mathrm{C})$ at all TEA concentrations. Error bars mark SD. 


\section{Figure 4:}

Quinidine selectively reduces the LVA component of $\mathrm{I}_{\mathrm{K}(\mathrm{V})}$. Current traces of $\mathrm{I}_{\mathrm{K}(\mathrm{V})}$ under control conditions (A) and after perfusion with $500 \mu \mathrm{M}$ quinidine (B). Measurements made as in Fig. 2. C. Normalized g/V relationship of the total conductance in 3 PD neurons under control conditions $(\boldsymbol{a})$ and after equilibration with $100 \mu \mathrm{M}$ quinidine $(\bullet)$, and $500 \mu \mathrm{M}$ quinidine $(\boldsymbol{\Delta})$. D. Normalized $\mathrm{g} / \mathrm{V}$ relationship of quinidine- blocked conductance after equilibration with $100 \mu \mathrm{M}$ quinidine $(\boldsymbol{\square})$, and $500 \mu \mathrm{M}$ quinidine (•), calculated as in Fig. 3. The shape of the g/V plot shows a selective block of the LVA component at $100 \mu \mathrm{M}$ quinidine, but quinidine also affects the HVA component at higher concentrations.

\section{Figure 5:}

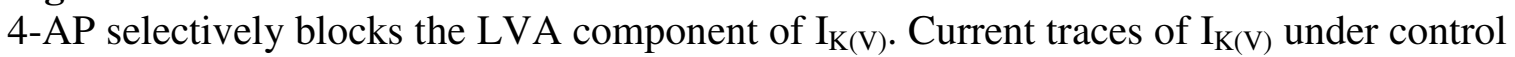
conditions (A) and after perfusion with $10 \mathrm{mM} 4-\mathrm{AP}$ (B). C. Normalized g/V relationship of the total conductance in 5 PD neurons under control conditions ( $\mathbf{})$, after equilibration with $4 \mathrm{mM}$ 4-AP $(\bullet), 10 \mathrm{mM}$ 4-AP $(\boldsymbol{\Delta})$, and 20mM 4-AP $(\boldsymbol{\nabla})$. D. Normalized g/V relationship of 4-AP-sensitive conductance after equilibration with $4 \mathrm{mM} 4-\mathrm{AP}(\mathbf{\square})$, $10 \mathrm{mM} 4-\mathrm{AP}(\bullet)$, and $20 \mathrm{mM} 4-\mathrm{AP}(\boldsymbol{\Delta})$. The shape of the $\mathrm{g} / \mathrm{V}$ plot shows selective but incomplete block of the LVA component at $4 \mathrm{mM} 4-\mathrm{AP}$, and a less selective block of both LVA and HVA components at higher concentrations.

\section{Figure 6:}

DA enhances $I_{K(V)}$ in the $A B$ neuron. A-C show current traces of an $A B$ neuron under control (A), after 5' perfusion with 0.1mM DA (B) and after 30' wash (C). D. normalized $\mathrm{g} / \mathrm{V}$ relationship of $\mathrm{I}_{\mathrm{K}(\mathrm{V})}$ total conductance under control $(\boldsymbol{\bullet})$, DA $(\bullet)$ and wash $(\boldsymbol{\Delta})$ for 4 $\mathrm{AB}$ neurons. The asterisk at the $+10 \mathrm{mV}$ step marks the voltage above which the DA trace differs significantly from the control and wash.

\section{Figure 7:}

DA enhances $\mathrm{I}_{\mathrm{K}(\mathrm{V})}$ in most PY neurons. A-C show current traces of a PY neuron under control (A), after 5' perfusion with $0.1 \mathrm{mM}$ DA (B) and after 20' wash (C). D. Normalized $\mathrm{g} / \mathrm{V}$ relationship of $\mathrm{I}_{\mathrm{K}(\mathrm{V})}$ total conductance under control $(\boldsymbol{\bullet})$, DA $(\bullet)$ and wash $(\boldsymbol{\Delta})$ for $9 \mathrm{PY}$ neurons. The asterisk at the $0 \mathrm{mV}$ step on the DA trace marks the voltage from which it differs significantly from the control. Error bars mark SD. In some pyloric neurons such as this one, the total current appears to show some inactivation at high voltages, which is eliminated by DA. This may reflect a small contamination of the current with $\mathrm{I}_{\mathrm{A}}$, which was not completely eliminated by holding at $-40 \mathrm{mV}$. DA reduces $\mathrm{I}_{\mathrm{A}}$ in PY neurons (Harris-Warrick et al., 1995), possibly explaining this modest effect. E. Percent change in steady state $\mathrm{I}_{\mathrm{K}(\mathrm{V})}$ at $+40 \mathrm{mV}$ after perfusion with DA in 9 different PY cells. 


\section{Figure 8:}

DA effect on separated LVA and HVA components of $\mathrm{I}_{\mathrm{K}(\mathrm{V})}$ in PY neurons. $\mathrm{g} / \mathrm{V}$ relationships of the low voltage-activated (LVA) component (A), and high voltageactivated (HVA) component (B) under control ( $\bullet$ ), after 5 ' perfusion with $0.1 \mathrm{mM} \mathrm{DA}(\bullet)$ and after 15' wash $(\boldsymbol{\Delta})$. The asterisk marks the voltages in DA above which the increase becomes significant $(\mathrm{p}<0.05)$. C,D: \% change of the LVA (C) and HVA (D) components under DA in all 9 PY neurons at $+40 \mathrm{mV}$. Note that the cells are grouped according to the

$\%$ change in conductance. The shades of grey correspond to the same neurons in $\mathrm{C}$ and D. 


\begin{tabular}{|c|c|c|c|c|c|}
\hline $\begin{array}{l}\text { Neuron } \\
\text { type }\end{array}$ & $\begin{array}{l}\mathbf{g}_{(\max )} \\
\mathbf{L V A}(\mu \mathrm{S})\end{array}$ & $\begin{array}{l}\mathbf{V}_{1 / 2} \text { comp } \\
(\mathbf{L V A})(\mathrm{mV})\end{array}$ & $\begin{array}{l}\text { slope comp. } \\
\text { (LVA) }\end{array}$ & $\begin{array}{l}\text { HVA amp @ } \\
+40 \text { mV }(\mu S)\end{array}$ & $\begin{array}{l}\text { LVA:HVA ratio } \\
(@+40 \mathrm{mV})\end{array}$ \\
\hline PD $(n=69)$ & $0.29 \pm 0.11$ & $-9.5 \pm 3.0$ & $-8.3 \pm 2.2$ & $0.20 \pm 0.15$ & $1.5: 1$ \\
\hline $\mathbf{L P}(\mathrm{n}=23)$ & $0.35 \pm 0.12$ & $-12.3 \pm 2.9$ & $-7.3 \pm 2.2$ & $0.29 \pm 0.27$ & $1.2: 1$ \\
\hline PY $(n=21)$ & $0.25 \pm 0.06$ & $-10.8 \pm 2.9$ & $-7.1 \pm 2.0$ & $0.16 \pm 0.19$ & $1.6: 1$ \\
\hline VD $(n=16)$ & $0.25 \pm 0.08$ & $-9.6 \pm 1.8$ & $-8.2 \pm 1.8$ & $0.27 \pm 0.16$ & $0.9: 1$ \\
\hline IC $(n=7)$ & $0.21 \pm 0.08$ & $-9.2 \pm 3.6$ & $-9.6 \pm 2.7$ & $0.11 \pm 0.05$ & $1.9: 1$ \\
\hline$\overline{A B}(n=9)$ & $0.19 \pm 0.04$ & $-7.8 \pm 2.5$ & $-10.2 \pm 1.7$ & $0.06 \pm 0.03$ & $3.2: 1$ \\
\hline
\end{tabular}

Table 1:

Properties of low voltage-activated (LVA) and high voltage-activated (HVA) components of $\mathrm{I}_{\mathrm{K}(\mathrm{V})}$ in pyloric neurons. Values are given with SD.

\begin{tabular}{|l|l|l|l|}
\hline LVA component values alone after separation and re-fit \\
\hline & $\mathbf{g}(\mathbf{m a x})($ in $\mu \mathrm{S})$ & $\mathbf{V}_{\mathbf{1 / 2}}$ (in $\left.\mathrm{mV}\right)$ & slope \\
\hline PY control & $0.22 \pm 0.08$ & $-11.5 \pm 3.2$ & $-6.8 \pm 2.5$ \\
\hline DA & $0.26 \pm 0.08 *$ & $-9.7 \pm 3.4$ & $-7.5 \pm 2.9$ \\
\hline Wash & $0.24 \pm 0.07$ & $-9.1 \pm 2.8$ & $-8.2 \pm 3.2$ \\
\hline
\end{tabular}

Table 2:

Effect of Dopamine on the low voltage-activated (LVA) component of $\mathrm{I}_{\mathrm{K}(\mathrm{V})}$ in PY neurons. Values are given with SD. Asterisk marks significant difference $(\mathrm{p}<0.05)$ 


\section{Figure 1}
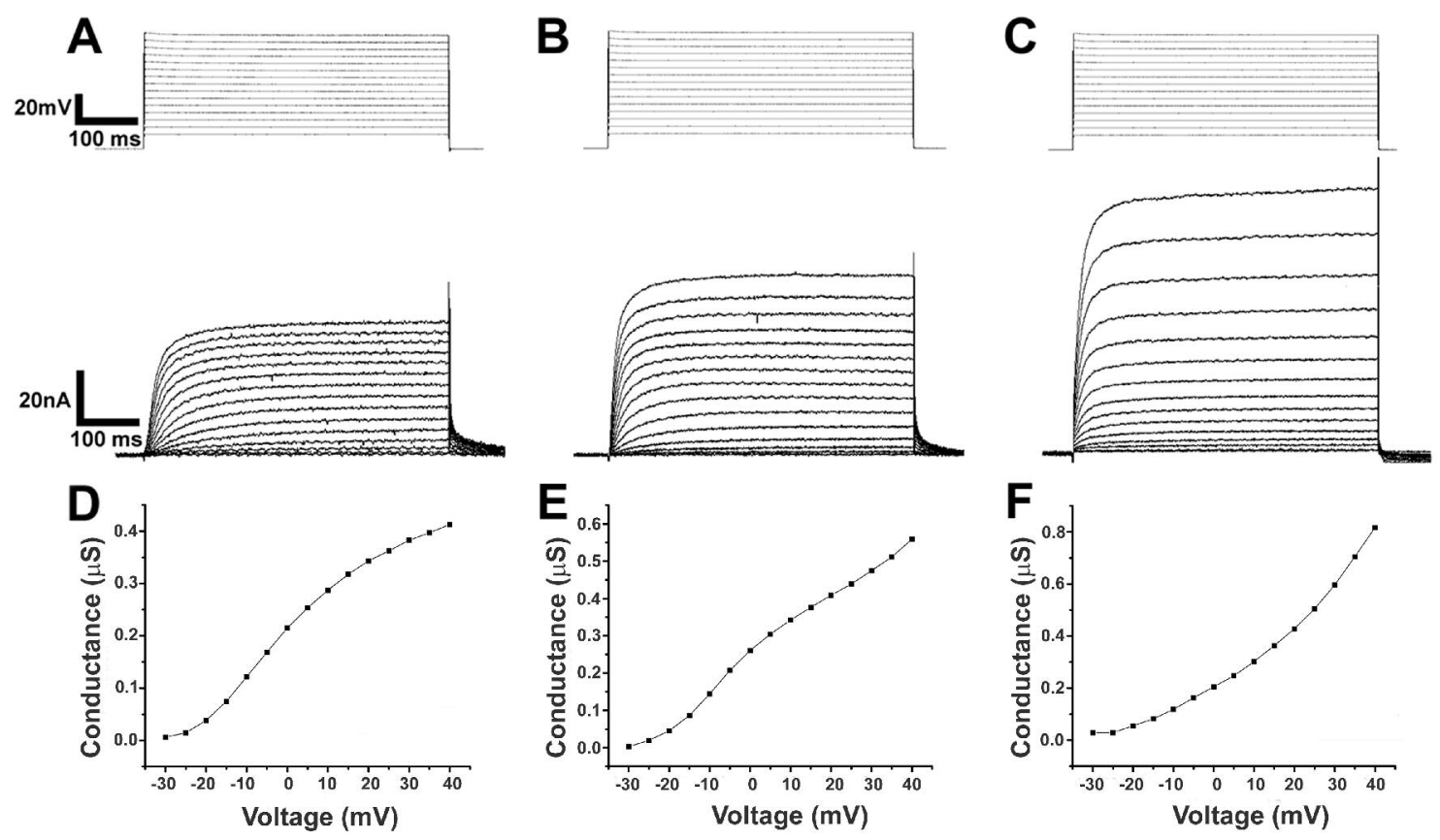
Figure 2:

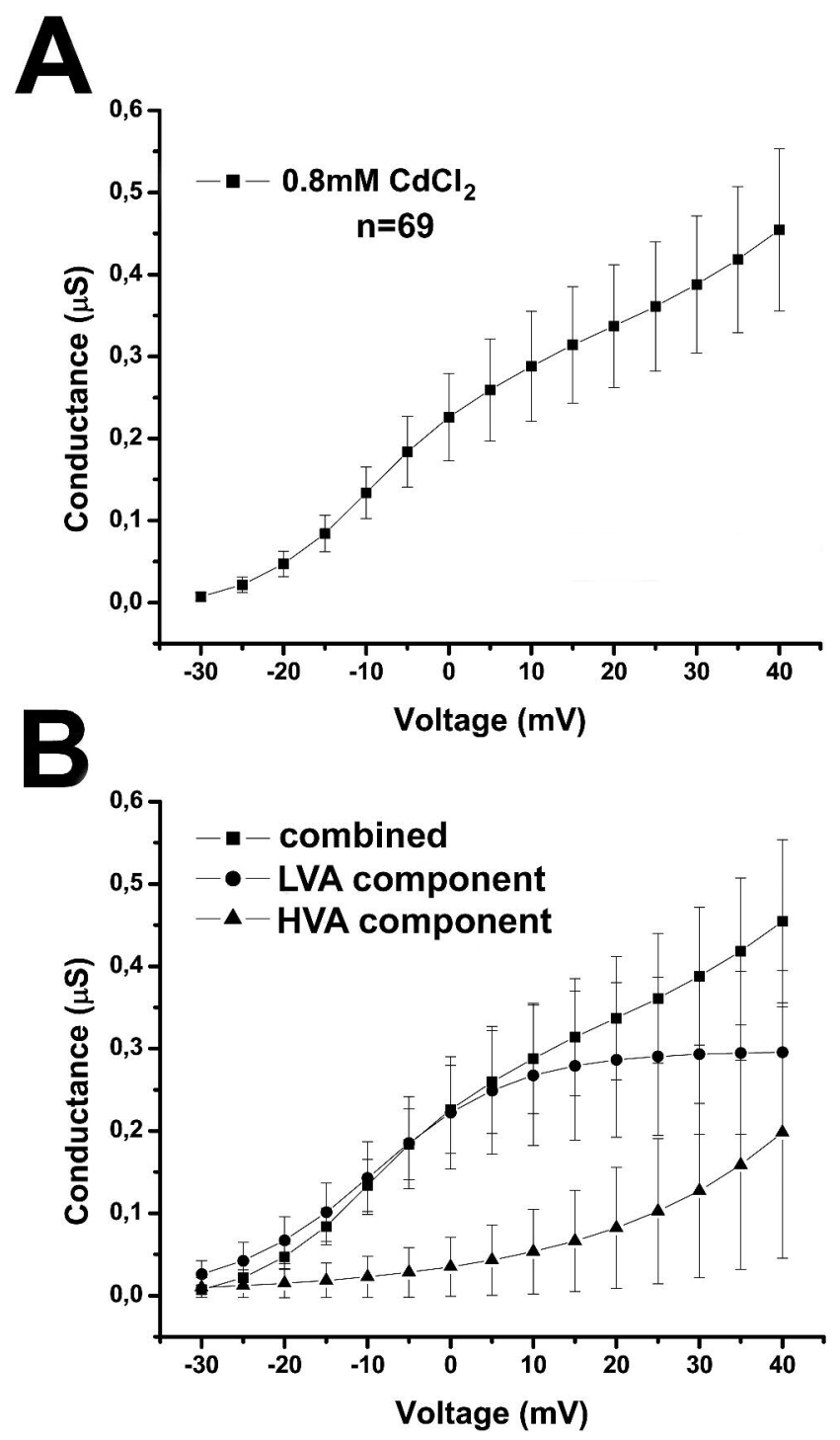


Figure 3:

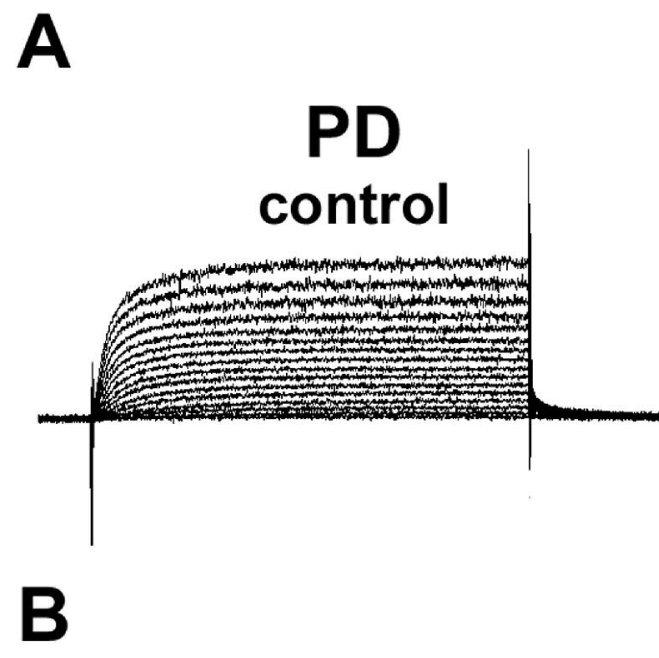

\section{C total conductance}

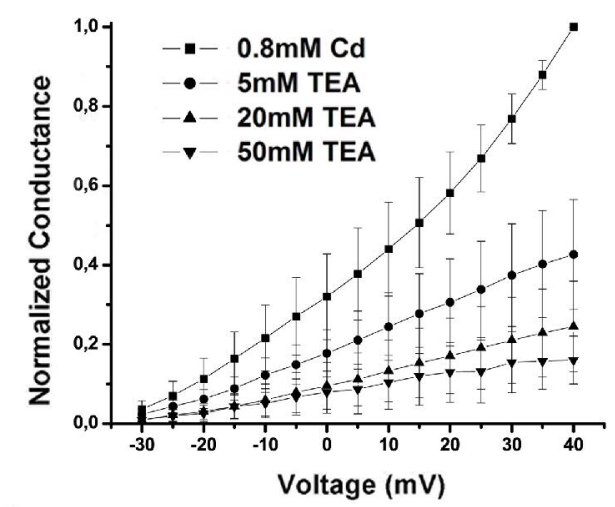

\section{TEA-blocked conductance}

\section{0 mM TEA}
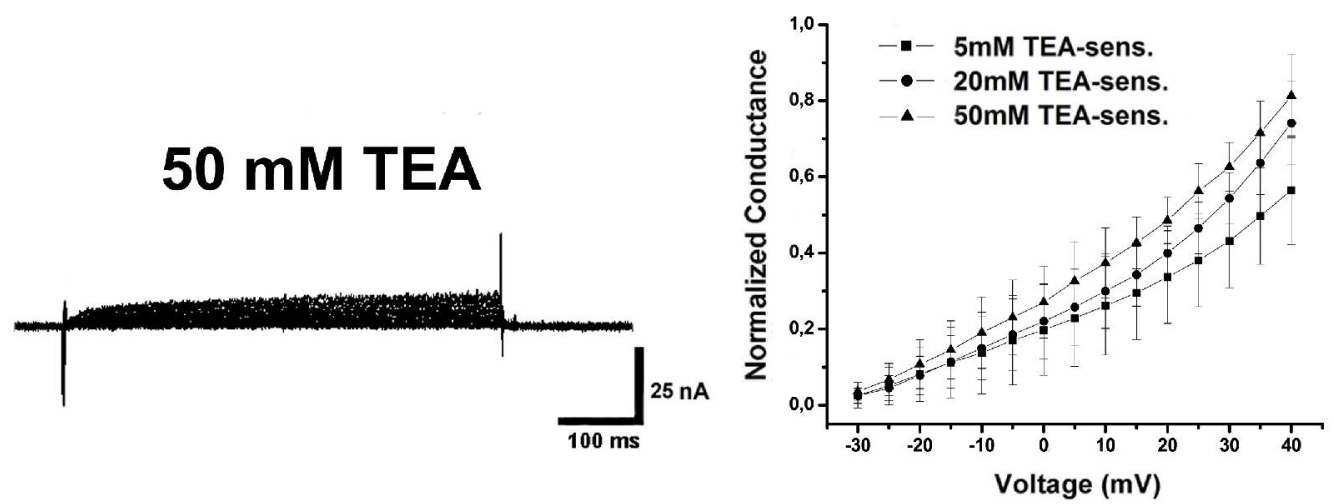
Figure 4:

A

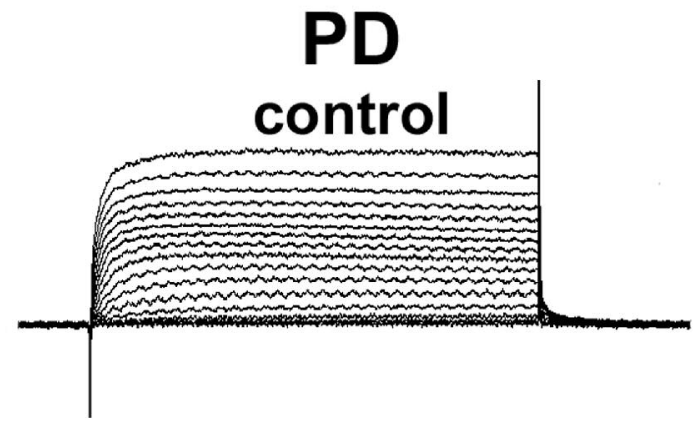

B
C total conductance

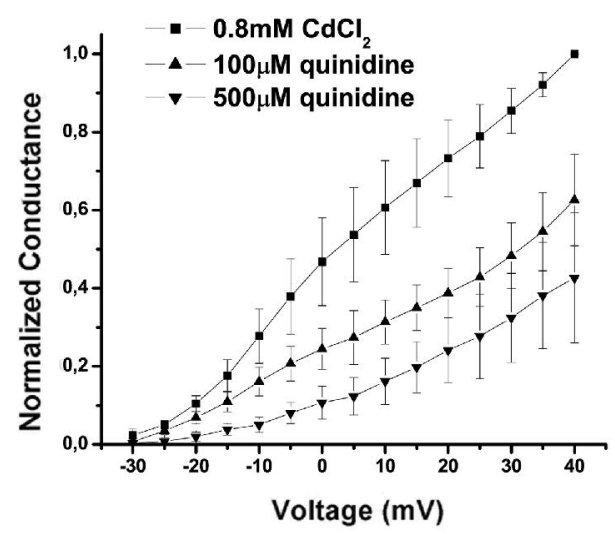

D quinidine-blocked conductance

\section{$500 \mu \mathrm{M}$ quinidine}
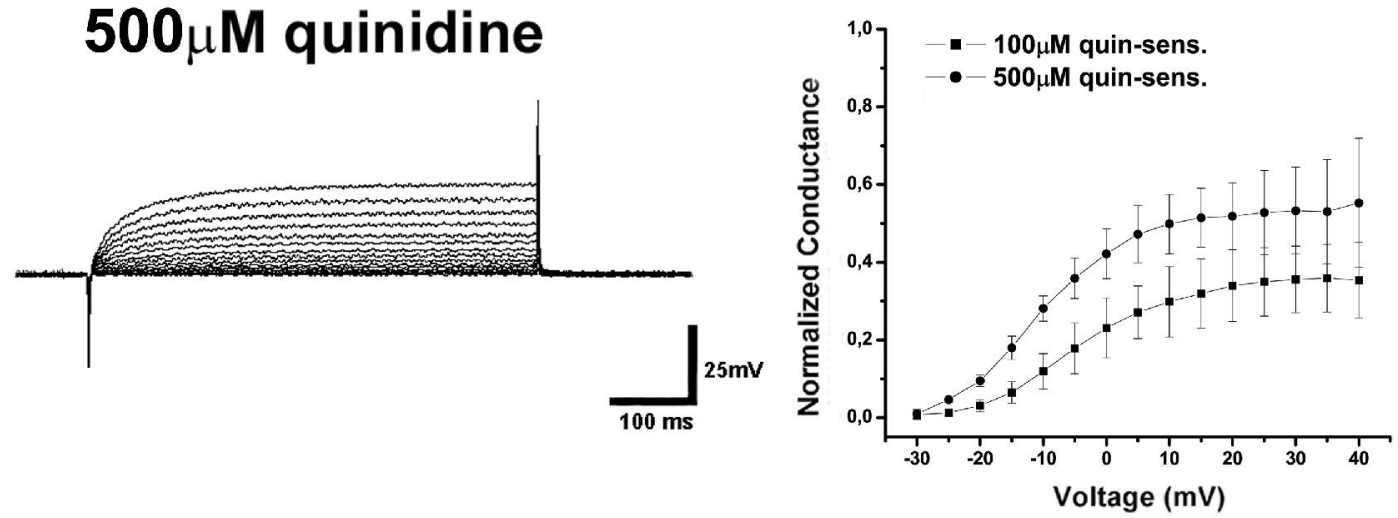
Figure 5:

A

C total conductance
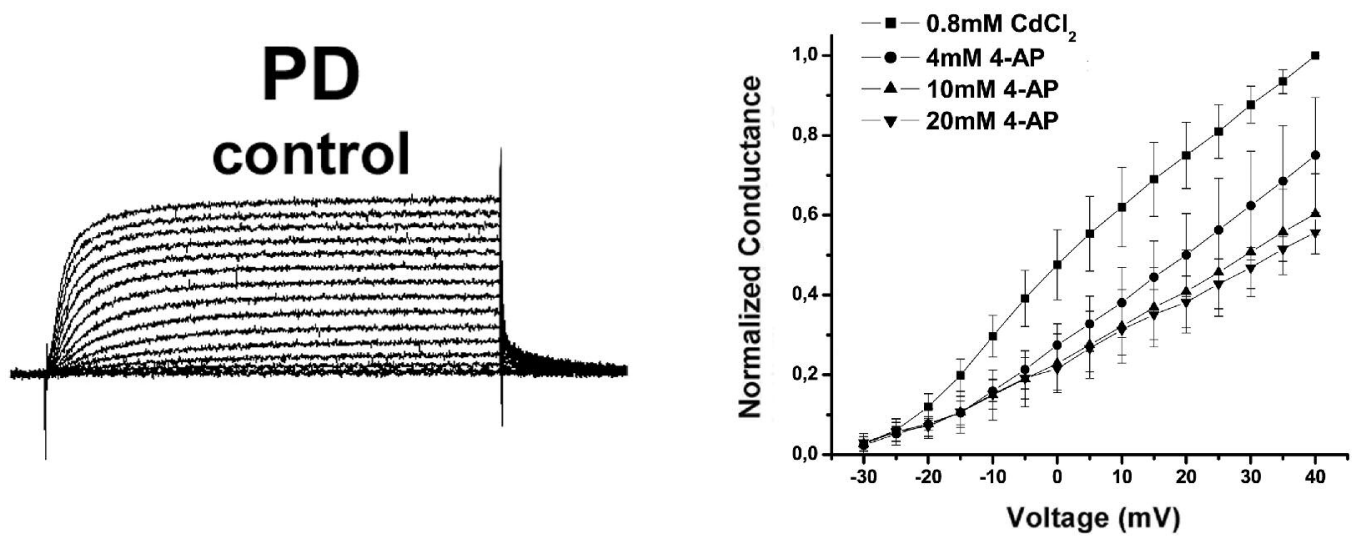

B

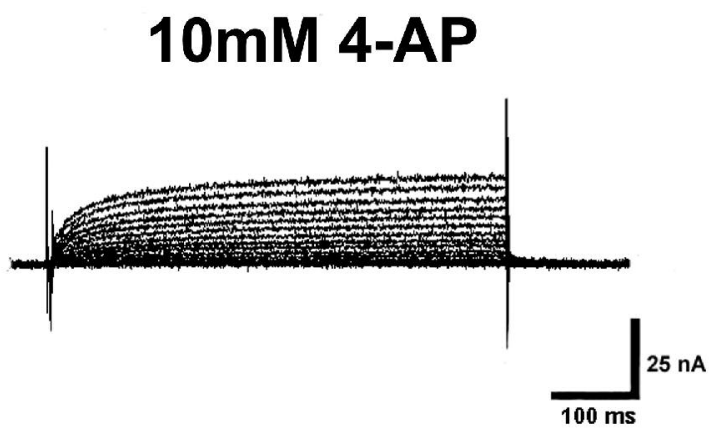

D 4-AP blocked conductance

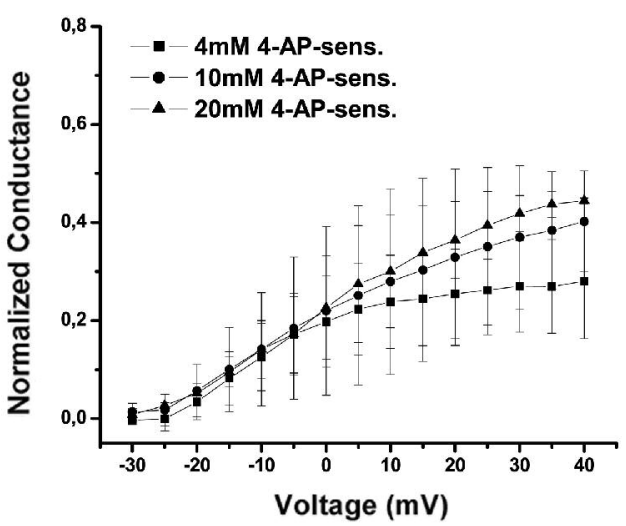


Figure 6:

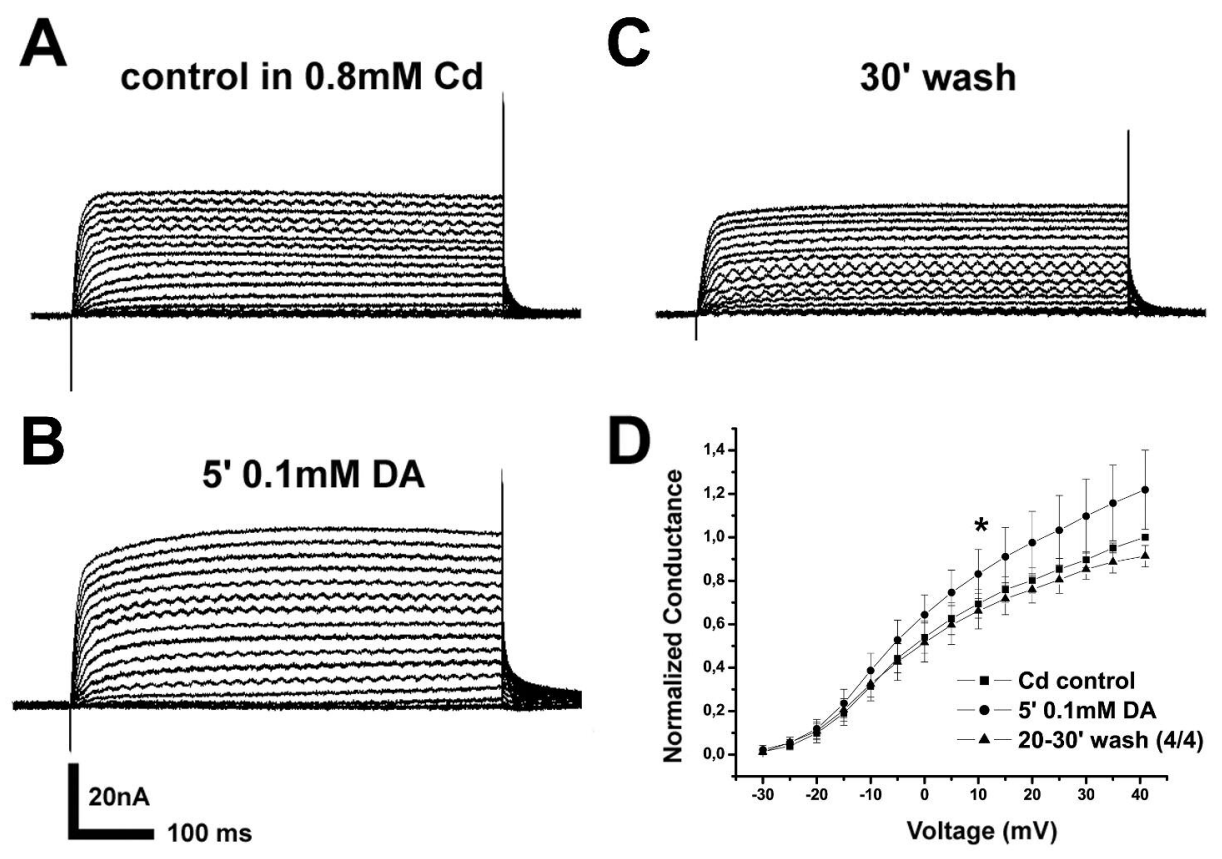


Figure 7:

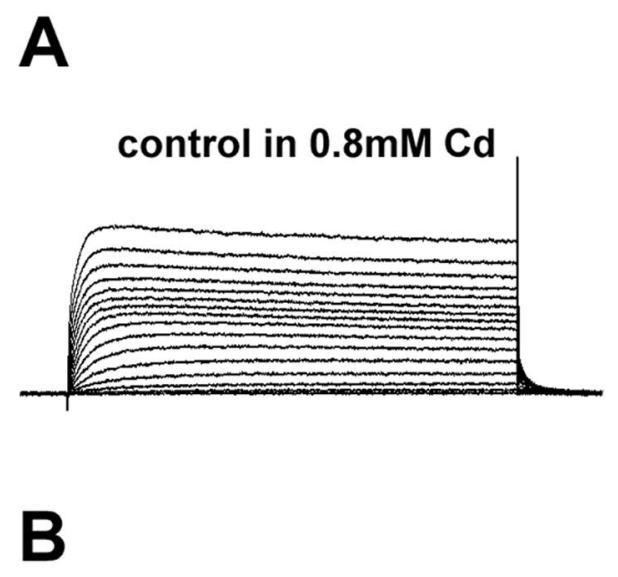

D
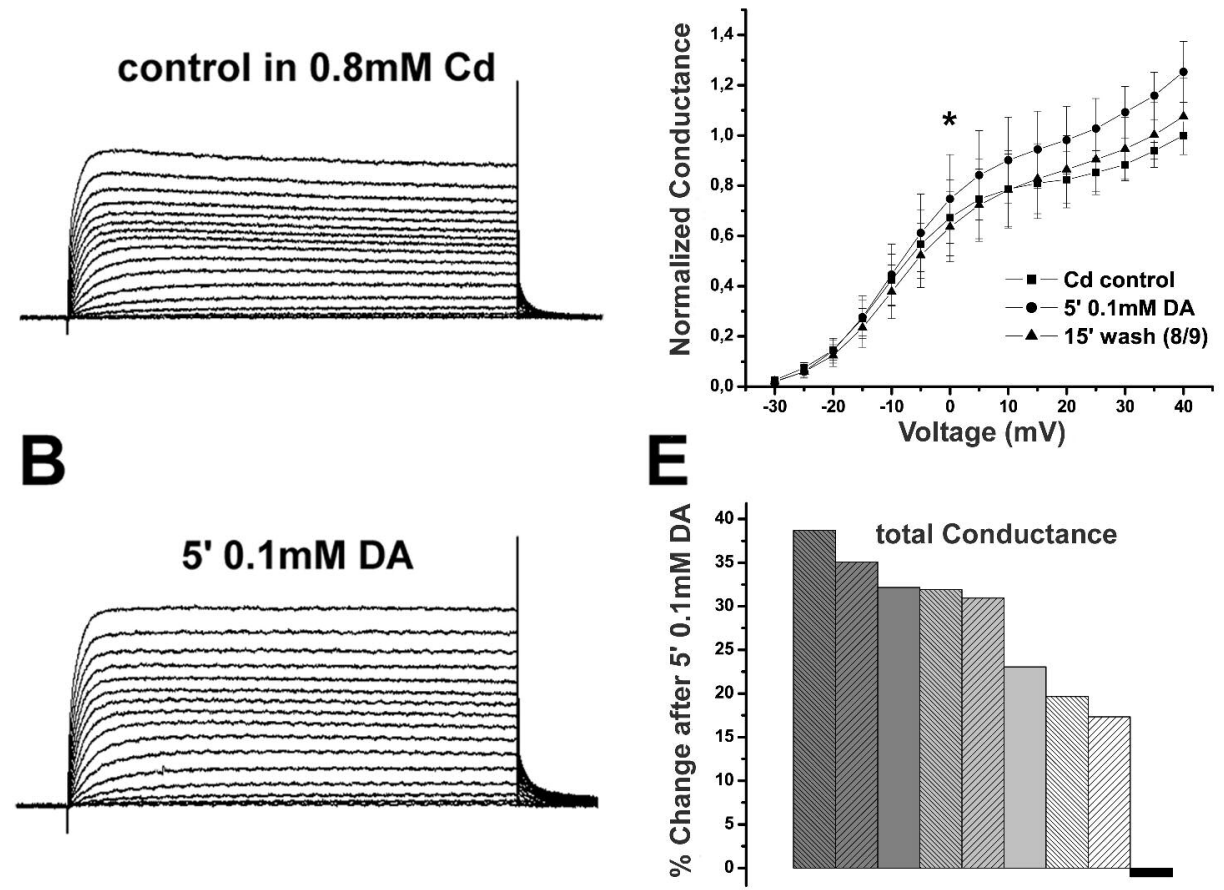

C

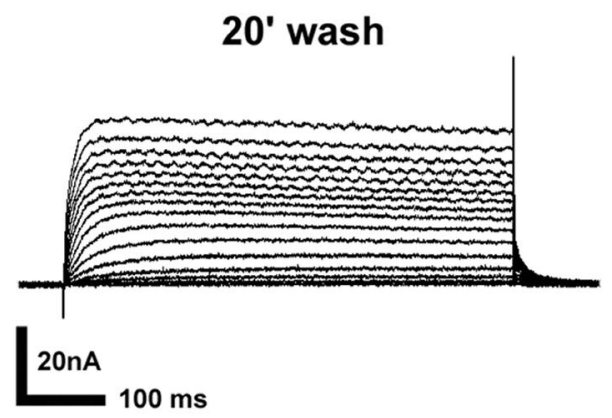


Figure 8:
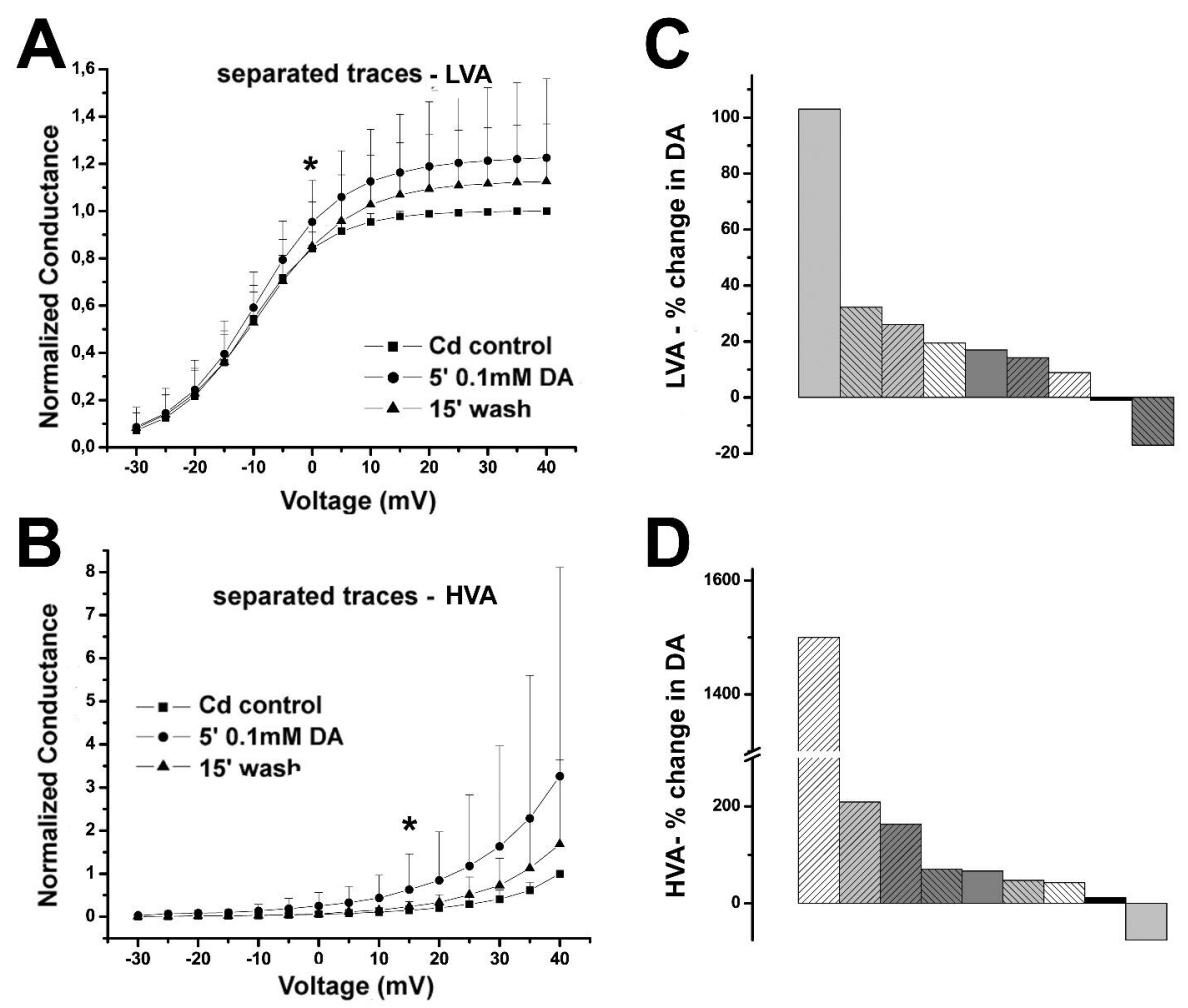